\title{
Auctions with Bid Credits and Resale*
}

\author{
Simon Loertscher ${ }^{\dagger} \quad$ Leslie M. Marx ${ }^{\ddagger}$
}

May 19, 2017

\begin{abstract}
Bid credits favoring subsets of bidders are routinely imposed on auctions and procurement auctions. These bid credits result in inefficient auction outcomes, which create pressure for postauction resale or, in a procurement context, for subcontracting. We show that the presence of resale, in turn, affects bidding strategies in such a way that auction outcomes are more likely to be inefficient and less informative, making it harder for resale to correct inefficiencies. The negative effects of bid credits and resale can be mitigated through direct restrictions on resale, tight caps on credits, reserve prices, anonymous bidding, and enhanced competition.
\end{abstract}

Keywords: designated entities, spectrum license auctions

JEL Classification: C72, D44, L13

*We thank Yongmin Chen (the editor) and two anonymous referees as well as Jonathan Levy, Eliot Maenner, Ilya Segal, Martha Stancill and seminar participants at Duke University, EARIE 2016, the Econometric Society Australasian Meeting 2014, and the ESEI/UTS Conference in Honor of John Ledyard for valuable comments and suggestions. We thank Federico Mini and Hoël Wiesner for valuable research assistance.

${ }^{\dagger}$ Department of Economics, Level 4, FBE Building, 111 Barry Street, University of Melbourne, Victoria 3010, Australia. Email: simonl@unimelb.edu.au.

${ }^{\ddagger}$ The Fuqua School of Business, Duke University, 100 Fuqua Drive, Durham, NC 27708, USA: Email: marx@duke.edu. 


\section{Introduction}

Percentage bid preferences are widely imposed on auction designers, for example, in the United States, Canada, Australia, and New Zealand. ${ }^{1}$ The "Buy American Act" provides for a $6 \%$ bid preference for domestic bidders and $12 \%$ for domestic small business bidders. ${ }^{2}$ A survey of U.S. state procurement laws, regulations, and policies finds that twenty-five states provide bid preferences or set-asides for in-state bidders or products, and the preference is mandatory in seventeen of the states. $^{3}$ The U.S. Federal Communications Commission (FCC) addresses the legislative requirement that its spectrum license auctions "disseminat[e] licenses among a wide variety of applicants" 4 by offering percentage bid credits for small businesses. ${ }^{5}$ The dollar amount of commerce involved in auctions and procurements with bid credits and/or other preferences is large. ${ }^{6}$ Typically, bid credits are hard-wired into legislation whereas the specifics of the auction format, the precise rules of the auction, and the possibility of resale or subcontracting are not.

Bid credits for preferred bidders have recently received increased attention. Dish Network Corporation's partnership with two bidders that received $25 \%$ bid credits amounting to $\$ 3.3$ billion in discounts at an FCC auction ending in early 2015 has been the subject of much controversy. ${ }^{7}$ The debate largely focuses on concerns related to the promotion of opportunities for small and rural businesses together with a desire to avoid the "unjust enrichment" of undeserving parties. Recent rule changes triggered by this debate include the relaxation of revenue thresholds to qualify for bid credits, the introduction of a new $15 \%$ bid credit for eligible rural service providers, and the imposition of a cap on the dollar amount of bid credits. ${ }^{8}$

By construction, bid credits favor some bidders over others. Thus, bid credits induce inefficient auction outcomes some of the time. These inefficiencies open the scope for gains from trade between the favored winner and the disfavored runner-up. Because pressure from these parties to execute mutually beneficial trades can be hard to resist, auctions with bid credits may almost inevitably

\footnotetext{
${ }^{1}$ Preferences for domestic content include $10 \%$ in Canada, 20\% in Australia, and 10\% in New Zealand (McAfee and McMillan, 1989).

${ }^{2}$ U.S. Federal Acquisition Regulation, FAR 25.105(b). In a procurement setting, percentage bid preferences are typically implemented by specifying that the preferred bidder wins and is paid her bid as long as her bid is within a specified percentage of the lowest bid.

${ }^{3}$ National Association of State Procurement Officials, 2012, pp. 11-13. Bid preferences in the range of $5 \%-$ 15\% appear common (Virginia Department of General Services, 2010). For example, the California Department of Transportation gives a $5 \%$ bid credit to small businesses in auctions for road construction contracts Marion (2007).

${ }^{4}$ Telecommunications Act of 1996, Pub. LA. No. 104-104, 110 Stat. 56 (1996), Section 309(j)(3), available at http://transition.fcc.gov/Reports/1934new.pdf.

${ }^{5}$ The FCC's program for "designated entities" has typically offered bid credits for small businesses and very small businesses (defined in term of previous years' gross revenues) of $15 \%$ and $25 \%$, respectively. See, e.g., FCC Auction 73 Procedures Public Notice, p. 22, available at http://hraunfoss.fcc.gov/edocs_public/attachmatch/DA-07-4171A1.pdf.

${ }^{6}$ According to Marion (2007, p. 1592), "Through various preference programs, the U.S. federal government in 2001 awarded $\$ 21.3$ billion of procurement contracts to small firms, minority and women owned businesses, companies located in economically disadvantaged areas, and veteran-owned businesses. This represents nearly 10 percent of the $\$ 216$ billion federal procurement market."

7 "FCC Poised to Reject Dish Partners' Spectrum Discounts," Wall Street Journal, July 16, 2015.

${ }^{8}$ The FCC revised its bid credits in July 2015 (Report and Order in the Matter of "Updating Part 1 Competitive Bidding Rules" http://transition.fcc.gov/Daily_Releases/Daily_Business/2015/db0721/FCC-15-80A1.pdf). No changes were made related to the five year unjust enrichment period and associated bid credit repayment schedule.
} 
be associated with resale or, in a procurement context, subcontracting. The interplay between bid credits and resale is what we study in this paper. Although resale may naturally and intuitively be thought of as correcting inefficiencies due to the distorting effects of bid credits, we show that if resale is anticipated by bidders, the option of resale may exacerbate rather than mitigate these inefficiencies. This insight is relevant for auction designers whose policies and procedures affect the ease with which resale transactions are possible. ${ }^{9}$ Although restrictions on resale limit the ability of later market transactions to correct inefficiencies in the auction outcome, they may be essential to the ability of the seller to achieve his objectives. ${ }^{10}$

We study both ascending-price auctions and second-price auctions. We show that bid credits provide incentives for preferred bidders to bid above their values in both. By overbidding, preferred bidders trade off the risk of negative surplus from the purchase against the possibility of positive surplus from resale. Overbidding leads to inefficient auction outcomes with positive probability, which creates the possibility for gains from post-auction resale or, in a procurement context, from subcontracting. It is tempting for an auctioneer subject to bid credits, such as a government agency procuring goods and services or selling government owned assets, to try to eliminate these inefficiencies by facilitating post-auction resale and subcontracting. However, facilitating resale is not necessarily a useful reaction because it may in fact exacerbate inefficiencies as explained next.

The mechanisms at work in our model are as follows. The presence of resale causes preferred bidders to bid higher in anticipation of possibly profiting from resale if they win, which we refer to as speculative bidding, adopting the terminology of Hafalir and Krishna (2008, 2009), Pagnozzi and Saral (2016a,b), and Pagnozzi (2010). ${ }^{11}$ Speculative bidding induces nonpreferred bidders to bid lower in counterspeculative anticipation of possible gains from purchasing the object on the resale market if they lose. ${ }^{12}$ An important effect of counterspeculative bid shading is that the nonpreferred bidders' bid strategies partly or completely obfuscate the nonpreferred bidders' values. Because resale markets are subject to private information problems similar to the primary auction market, such obfuscation makes it more difficult for the resale market to correct the inefficiencies arising from the auction. Complete obfuscation occurs when a nonpreferred bidder essentially abstains from the auction, preferring his chances of obtaining the asset in the resale market to any serious bid in the auction against the aggressive bidding by the preferred bidders, whose bids are inflated both because of the bid credit and because of the expected gains from resale. The prospect of resale, which leads to speculative and counterspeculative bidding, makes resale more desirable to correct

\footnotetext{
${ }^{9}$ Resale can be hindered by, for example, holding requirements or uncertainty regarding whether subsequent transactions would be approved. The FCC restricts the ability of bidders receiving bid credits to lease or resell spectrum licenses that they win at auction (see Section 1.2110(b)(3)(iv) of the FCC's rules). In a procurement context, there may be restrictions on subcontracting. See Marion (2007) on subcontracting restrictions in California highway auctions.

${ }^{10}$ As noted by Wilson (1993, p. 11), excluding or limiting resale is essential to the effectiveness of nonlinear pricing.

${ }^{11}$ Haile $(2000,2001,2003)$ uses the terminology "resale seller effect" for the increased payoff to a winner and "resale buyer effect" for the increased payoff to a loser due to resale.

${ }^{12}$ Pagnozzi and Saral (2016b) refer to the counterpart to speculative bidding as "non-speculative" bidding. In a related context, Xu, Levin, and Ye (2013) refer to "speculative entry" and "resale hunting." Pagnozzi (2010) analyzes similar effects in multi-object auctions.
} 
inefficient auction outcomes but less effective at doing so because of the resulting obfuscation.

A consequence of the three effects of bid credits and resale on bidding - speculative bidding by preferred bidders, counterspeculative bidding by nonpreferred bidders, and the resulting obfuscationis that the overall effect of facilitating resale on expected social surplus is far from obvious. If resale frictions are sufficiently low, a nonpreferred bidder prefers to obfuscate and lose the auction rather than reveal information about his type that would disadvantage him in the resale game. In this case, equilibrium outcomes are unique and marginal reductions in resale frictions increase the likelihood that resale occurs and so increase expected social surplus. However, if resale frictions are sufficiently severe that there is no resale, then marginal reductions in resale frictions can decrease expected social surplus because the distortions to bidding behavior as a result of resale can outweigh the ability of resale to remedy inefficiencies in the auction outcome. Further, we show that from a social surplus perspective, counterintuitively, higher bid credits should be combined with fewer restrictions on resale, whereas smaller bid credits should be accompanied with more restrictions on resale. $^{13}$

We discuss possible remedies for the distortions that arise in auctions with bid credits when resale is possible. We show that distortions can be reduced by imposing reserve prices, despite creating the possibility that the object is not sold at all. In addition, distortions can be reduced by using anonymous bidding, which renders the identities of active and exited bidders unobservable for the remaining bidders. We show that caps on the dollar amount of credit that a preferred bidder can receive need not eliminate equilibria with extreme distortions such as those with complete obfuscation. Although caps can be effective at improving outcomes if they are chosen tightly enough, a cap that is effective absent resale need not be so with resale.

There is a sizeable related literature on the effects of resale when auction outcomes are inefficient. To the best of our knowledge, ours is the first paper to relate resale to auctions that are inefficient because of bid credits. Two of the most closely related papers are Hafalir and Krishna (2008) and Lebrun (2010b), which analyze auctions with resale. We adapt Lebrun's (2010b) representation of the resale game of Hafalir and Krishna (2008), in which the winner makes a take-it-or-leave-it offer to the loser with some probability and the loser makes a take-it-or-leave-it offer with the complementary probability. Hafalir and Krishna (2008) focus on the revenue comparison between second-price and first-price auctions with a strong and a weak bidder and with resale. Although bid credits can be interpreted as making a preferred bidder an endogenously strong bidder, the analogy between our setup and Hafalir and Krishna's (2008) does not carry over to second-price and ascending auctions because asymmetries in distributions do not affect bidding behavior in these formats, whereas bid credits do affect bidding behavior in these formats.

The experimental results of Pagnozzi and Saral (2016a) illustrate how an increase in the probability that the resale market operates can result in less efficient auction outcomes, and thus less efficient final outcomes, in a setup with two units for sale and two asymmetric bidders, one strong

\footnotetext{
${ }^{13}$ Of course, if the goal is to prevent the unjust enrichment of preferred bidders, then the conclusions may be different.
} 
bidder with two-unit demand and one weak bidder with single-unit demand. In their setup, resale increases demand reduction by the strong bidder and speculation by the weak bidder, but efficiency is restored by resale (strong and weak type distributions do not overlap) when the resale market operates. Because resale in our model is affected by private information, bidding distortions affect not only the auction, but also the efficiency of the resale market.

Gupta and Lebrun (1999) also consider resale following a first-price auction with asymmetric bidders. However, they assume that all values are revealed after the auction, so auction outcomes do not affect beliefs in the resale game and the ultimate outcome is efficient. With commonly known values and wealth constraints, Pagnozzi (2007) shows that bidders may prefer losing in the auction in order to benefit from post-auction resale opportunities. Xu, Levin, and Ye (2013) show that selection based on participation costs can lead high-valuing (or high-cost) bidders not to participate in an auction.

Auction inefficiencies and scope for resale arise in Haile (2003) because bidders do not know their values until after the auction and in Garratt and Tröger (2006) because one bidder is known to have value zero. ${ }^{14}$ We focus on the independent private values framework as do Garratt and Tröger (2006), who find that resale may lead the bidder with value zero to bid a positive amount and other bidders with low values to pool at a bid of zero. In our model, resale may lead a preferred bidder with value zero to bid a positive amount and nonpreferred bidders to pool at zero for all values. ${ }^{15}$ As in Lebrun (2010a) and Lebrun (2012), the ratchet effect implies that there is no strictly increasing pure strategy equilibrium bid function for a nonpreferred bidder.

The above mentioned papers and our paper analyze setups in which resale affects auction outcomes. There is also a strand of literature on auctions and mechanism design with resale that shows that resale need not reduce the designer's ability to achieve his objective. For example, Zheng (2002), Ausubel and Cramton (2004), Lebrun (2012), and Zhang and Wang (2013) show that the designer's ability to achieve Myerson's (1981) optimal auction outcomes or the property that bidders have dominant strategies to bid truthfully in the auction need not be affected by the possibility of resale.

The remainder of this paper is organized as follows. In Section 2, we describe the setup. In Section 3, we characterize the equilibria, working backwards starting with the resale game and then considering bidding in an ascending auction with bid credits. In Section 4, we consider issues related to the multiplicity of equilibria. In Section 5, we examine the welfare effects of resale in the presence of bid credits. In Section 6, we discuss potential remedies for the negative effects of resale on auctions with bid credits. In Section 7, we discuss other auction formats. In Section 8, we conclude.

\footnotetext{
${ }^{14}$ On the effects of resale on efficiency, Hafalir and Krishna (2009) show that in a first-price auction with asymmetric bidders, resale may reduce final efficiency. Experimental papers by Pagnozzi and Saral (forthcoming, 2016) show that resale may reduce final efficiency in multi-object auctions.

${ }^{15}$ Pooling occurs only in the ascending auction of Garratt and Tröger (2006). In their first-price auction, there is no pooling and the bidder with zero value randomizes. Our focus is on noncooperative bidding as is Garratt and Tröger's. For effects of resale with collusive bidding, see Garratt, Tröger, and Zheng (2009).
} 


\section{Setup}

Our baseline model assumes an ascending auction for a single object with bid credits and the potential for post-auction resale.

There is at least one preferred bidder and at least one nonpreferred bidder. We refer to a preferred bidder as she and a nonpreferred bidder as he. Each preferred bidder draws her value from $F_{p}$, and each nonpreferred bidder draws his value from $F_{n}$, where the distributions have common support $[0, \bar{v}]$ and positive densities on $[0, \bar{v}] .{ }^{16}$ We assume regularity conditions hold. Specifically, we assume that the virtual value of a nonpreferred bidder whose value $v$ is distributed according to $F_{n}$ restricted to the support $[0, b], \Phi(v ; b) \equiv v-\frac{F_{n}(b)-F_{n}(v)}{f_{n}(v)}$, is nondecreasing in $v$ for all $v \in[0, \bar{v}]$ and $b \in[v, \bar{v}] .{ }^{17}$ Similarly, we assume that the virtual cost of the preferred bidder whose value is $v$ is distributed according to $F_{p}$ restricted to the support $[a, \bar{v}], \Gamma(v ; a) \equiv v+\frac{F_{p}(v)-F_{p}(a)}{f_{p}(v)}$, is nondecreasing in $v$ for all $v \in[0, \bar{v}]$ and $a \in[0, v]$. We begin by analyzing the model for the case with one preferred and one nonpreferred bidder. We relax this in Section 6.

The ascending auction model is similar to the "button auction" of Milgrom and Weber (1982). The price of the object rises continuously from zero and each bidder remains active until he or she exits. A bidder who has exited cannot reenter. When only one bidder remains active, the price stops if the price is greater than or equal to the reserve $r \geq 0$, and otherwise the price continues to rise until the final bidder exits or the reserve is reached and then stops. Ties between a preferred and nonpreferred bidder are broken in favor of the preferred bidder, and in the general model with multiple bidders of each kind, ties between agents of the same kind are broken randomly. We assume that the seller and bidders observe the exit points of all bidders other than the winner (even if those exits occur at a price below the reserve), except in our consideration of anonymous bidding in Section 6.

If the final price is greater than or equal to the reserve, then the object is awarded to the final active bidder at the final price (which is either the price at which the second-to-last bidder exited or the reserve), with preferred bidders receiving a bid credit $c \in[0,1)$ so that they pay only $1-c$ times the final price. Consequently, the "willingness to bid" of a preferred bidder with value $v$ given a bid credit $c$ is $v /(1-c)$.

For now, we assume that there is only one preferred and one nonpreferred bidder. We consider multiple bidders of each type when addressing anonymous bidding in Section 6.4. We denote the preferred bidder's bid function by $\rho:[0, \bar{v}] \rightarrow\left[0, \frac{\bar{v}}{1-c}\right]$ and the nonpreferred bidder's bid function by $\eta:[0, \bar{v}] \rightarrow[0, \bar{v}]$ (where $\rho$ looks like "p" for preferred and $\eta$ looks like "n" for nonpreferred). Specifically, the preferred bidder with value $v$ remains active if and only if the current auction price

\footnotetext{
${ }^{16}$ We can extend the model to allow each nonpreferred and each preferred bidder to draw his or her value from a different distribution, all with the same support, but the notation is greatly simplified by assuming that preferred bidders are symmetric with each other and that nonpreferred bidders are symmetric with each other, so we adopt that assumption.

${ }^{17}$ The virtual value has the interpretation of marginal revenue and that virtual cost that of marginal cost, as first observed by Bulow and Roberts (1989), with the probability of trade being interpreted as quantity. Here the virtual type functions, due to Myerson (1981), are generalized to account for endogenous truncations.
} 
is less than $\rho(v)$, and the nonpreferred bidder with value $v$ remains active if and only if the current auction price is less than $\eta(v)$.

Absent resale, there is a unique equilibrium in dominant strategies. The dominant strategy for the nonpreferred bidder with value $v$ is to remain active until the price reaches $\eta(v)=v$, whereas the dominant strategy for the preferred bidder with value $v$ is to remain active until the price reaches her willingness to pay $\rho(v)=\frac{v}{1-c}$. That is, the preferred bidder simply inflates her bid to account for the discount in her payment due to the bid credit. We depict these bid functions in Figure 1 for a twenty percent bid credit and $\bar{v}=1$.

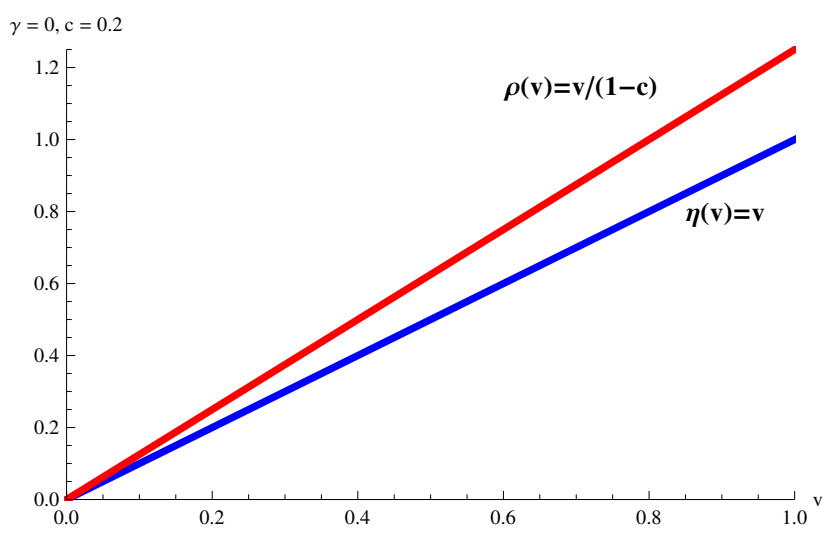

Figure 1: Bid functions for the case of no resale and a $20 \%$ bid credit.

Figure 1 illustrates that in equilibrium with no resale, it is possible for the preferred bidder to win when her value is less than that of the nonpreferred bidder. Denoting the nonpreferred and preferred bidders' values by $v_{n}$ and $v_{p}$, respectively, this occurs when the preferred bidder's value is less than $v_{n}$ but greater than $(1-c) v_{n}$. In this case, there are positive gains from trade from resale. However, when the nonpreferred bidder wins, there are no gains from trade from resale because $\eta\left(v_{n}\right)>\rho\left(v_{p}\right)$ implies $v_{n}>v_{p}$.

When the preferred bidder wins, we assume that with probability $\gamma \in[0,1]$ a resale game is played between the two bidders. When the nonpreferred bidder wins, we assume no resale game is played. Of course, this assumption can be relaxed with no change to the results if following a win by the nonpreferred bidder both bidders believe that there are no gains from resale. These beliefs are correct if resale is not anticipated because then, as just noted, $\eta\left(v_{n}\right)>\rho\left(v_{p}\right)$ implies $v_{n}>v_{p}$.

We assume that the resale game involves randomized take-it-or-leave-it offers, in which with probability $\lambda \in(0,1)$ the preferred bidder makes a take-it-or-leave-it offer to the nonpreferred bidder and with probability $1-\lambda$ the nonpreferred bidder makes a take-it-or-leave-it offer to the preferred bidder. Bidders choose their resale offers and accept/reject decisions to maximized their expected payoffs given their updated beliefs about the value of other bidder based on the observed bidding. If the offer is accepted, then the bidders transact at the offered price. If the offer is rejected, then there is no transaction. 


\section{Equilibrium}

We proceed by first considering the resale game in Section 3.1 and then considering equilibrium bidding at the auction in Section 3.2.

\subsection{Equilibrium of the resale game}

The optimal offers in the resale market can be described in terms of the players' virtual values and virtual costs. When the bidding has revealed the nonpreferred bidder's value to be in $[a, b]$, then the optimal resale offer by the preferred bidder with a value $v_{p}<b$ (if $v_{p} \geq b$ the preferred bidder believes there are no gains from resale) is the resale offer $t$ that solves

$$
\begin{aligned}
& \max _{t \in[a, b]} t \operatorname{Pr}\left(t \leq v_{n} \mid v_{n} \leq b\right)+v_{p} \operatorname{Pr}\left(v_{n}<t \mid v_{n} \leq b\right) \\
= & \max _{t \in[a, b]} t \frac{F_{n}(b)-F_{n}(t)}{F_{n}(b)-F_{n}(a)}+v_{p} \frac{F_{n}(t)}{F_{n}(b)-F_{n}(a)},
\end{aligned}
$$

which has first-order condition

$$
v_{p}=t-\frac{F_{n}(b)-F_{n}(t)}{f_{n}(t)}=\Phi(t ; b)
$$

Given our regularity assumption, the first-order condition characterizes the interior optimum, which we denote by $\Phi^{-1}\left(v_{p} ; b\right)$. Similarly, when the bidding has revealed the preferred bidder's value to in $[a, b]$, then the interior optimal resale offer by the nonpreferred bidder when his value is $v_{n}>a$ is $t$ such that $v_{n}=\Gamma(t ; a)$, which we denote by $\Gamma^{-1}\left(v_{n} ; a\right)$.

Summarizing, the optimal resale offer by a preferred bidder with value $v$ to a nonpreferred bidder whose value is believed to be in $[a, b]$ is

$$
o_{p}(v, a, b) \equiv \begin{cases}\max \left\{v, a, \Phi^{-1}(v ; b)\right\}, & \text { if } a<b \\ b, & \text { if } a=b \text { and } v \leq b \\ \bar{v}, & \text { if } a=b \text { and } v>a\end{cases}
$$

and the optimal purchase offer by a nonpreferred bidder with value $v$ to a preferred bidder whose value is believed to be in $[a, b]$ is

$$
o_{n}(v, a, b) \equiv \begin{cases}\min \left\{v, b, \Gamma^{-1}(v ; a)\right\}, & \text { if } a<b \\ a, & \text { if } a=b \text { and } v \geq a \\ 0, & \text { if } a=b \text { and } v<a\end{cases}
$$

By definition the price at which the preferred bidder offers to sell is above her value, $o_{p}(v, a, b) \geq v$, and the price at which the nonpreferred bidder offers to buy is below his value, $o_{n}(v, a, b) \leq v$.

When the preferred bidder wins, the bidding reveals a lower bound for the preferred bidder's value and a point or interval for the nonpreferred bidder's value depending on the nature of his bid 
function and the bid at which he exited. Let $R_{p}(v, \hat{v}, \ell, h)$ denote the expected net benefit from resale for the winning preferred bidder with value $v$ when her value is revealed to be at least $\hat{v}$, conditional on the nonpreferred bidder's value being in $[\ell, h]$ :

$$
\begin{aligned}
R_{p}(v, \hat{v}, \ell, h)= & \lambda\left(o_{p}(v, \ell, h)-v\right) \frac{1}{\operatorname{Pr}_{v^{\prime} \mid F_{n}}\left(v^{\prime} \in[\ell, h]\right)} \\
& +(1-\lambda) E_{v^{\prime} \mid F_{n}}\left[\max \left\{0, o_{n}\left(v^{\prime}, \hat{v}, \bar{v}\right)-v\right\} \mid v^{\prime} \in[\ell, h]\right] .
\end{aligned}
$$

Let $R_{n}(v, \hat{v}, \ell, h)$ denote the expected net benefit from resale for the nonpreferred bidder when his value is $v$ and is revealed to be in $[\ell, h]$, conditional on the preferred bidder's value being at least $\hat{v}$ :

$$
\begin{aligned}
R_{n}(v, \hat{v}, \ell, h)= & \lambda E_{v^{\prime} \mid F_{p}}\left[\max \left\{0, v-o_{p}\left(v^{\prime}, \ell, h\right)\right\} \mid \hat{v} \leq v^{\prime}\right] \\
& +(1-\lambda)\left(v-o_{n}(v, \hat{v}, \bar{v})\right) \operatorname{Pr}_{v^{\prime} \mid F_{p}}\left(v^{\prime}<o_{n}(v, \hat{v}, \bar{v}) \mid \hat{v} \leq v^{\prime}\right) .
\end{aligned}
$$

The preferred bidder's resale payoff $R_{p}(v, \hat{v}, \ell, h)$ is nonincreasing in $v$ and $\hat{v}$ because a winning preferred bidder's expected net benefit from selling the item in the resale market is weakly greater if her value for the item is lower or if the bidding reveals her value to be higher, in which case the expected resale offer from the nonpreferred bidder is higher. In addition, $R_{p}(v, \hat{v}, \ell, h)$ is nondecreasing in $\ell$ and $h$ because the preferred bidder's expected net benefit from resale is weakly greater if she expects the nonpreferred bidder, who is the buyer in the resale game, to have a value that is in an interval with a larger lower or upper support. Finally, if $v<\ell \leq h$, then $R_{p}(v, v, \ell, h)>0$ because a preferred bidder with value $v$ has positive expected payoff from resale when she faces a nonpreferred bidder whose value lies in a range above her value.

Turning to the nonpreferred bidder, $R_{n}(v, \hat{v}, \ell, h)$ is nondecreasing in $v$ because a higher value for the nonpreferred bidder weakly increases his expected payoff from purchasing the item in the resale market. In contrast, $R_{n}(v, \hat{v}, \ell, h)$ is nonincreasing in $\hat{v}$ because a higher value for the preferred bidder, who is the potential seller in resale, reduces the nonpreferred bidder's net expected payoff from resale. In addition, $R_{n}(v, \hat{v}, \ell, h)$ is nonincreasing in $\ell$ and $h$ because a higher revealed value for the nonpreferred bidder weakly increases the payment demand of the preferred bidder in the resale game.

\subsection{Equilibrium bidding}

To construct equilibrium bid functions, we begin by providing intuition for the effects of resale on an auction with bid credits and then characterize equilibrium bid functions. In this section, we focus on the case with a reserve price of zero. We discuss positive reserves in Section 6 .

\section{Speculative and counterspeculative bidding}

Consider the effects on the no-resale bid functions in Figure 1 from allowing a small positive probability that the resale market will operate. Focusing on a preferred bidder with value less than 
$\bar{v}$, the introduction of resale increases the benefit to a preferred bidder from winning the auction because the preferred bidder could gain from resale. Because resale increases the value to the preferred bidder from winning and does not change her value from losing, it provides an incentive for higher bids. We refer to this as the incentive for speculative bidding by the preferred bidder. For a preferred bidder with value $\bar{v}$, the introduction of resale does not increase her benefit from winning because there is no possibility of mutually beneficial resale in that case.

For the nonpreferred bidder, the introduction of resale increases the value from losing the auction because he may realize a positive payoff if he purchases the object at a price below his value in the resale market. In contrast, there are no such gains for the nonpreferred bidder from winning the auction. Thus, for a nonpreferred bidder with a positive value, resale increases the expected payoff from losing the auction but does not change his payoff from winning the auction. This means that the nonpreferred bidder has an incentive to bid lower than he would absent resale. We refer to this as the incentive for counterspeculative bidding. A nonpreferred bidder with value zero bids zero regardless of resale.

Taken together, these arguments show that with resale, i.e., with $\gamma>0$, the preferred bid function is weakly greater than without resale, i.e., $\rho(v) \geq \frac{v}{1-c}$, but anchored at the upper endpoint, $\rho(\bar{v})=\frac{\bar{v}}{1-c}$. The nonpreferred bid function is weakly lower, $\eta(v) \leq v$, but anchored at the origin, $\eta(0)=0$.

\section{Obfuscation}

It may seem natural to conjecture continuous increasing bid functions satisfying these conditions. However, there is no such equilibrium as we show next. Specifically, there is no equilibrium in which the nonpreferred bidder's bid function exhibits continuous and strictly increasing portions. To see this, note that given such a conjectured equilibrium, the change in the expected payoff of a nonpreferred bidder with value $v$ from increasing his bid marginally above $\eta(v)$ comes from the value associated with the increased probability of winning, which has two components: the value from winning, $v-\eta(v)$, and the lost expected resale payoff, $R_{n}\left(v, \rho^{-1}(\eta(v)), v, v\right)$, because there is no resale when the nonpreferred bidder wins. We can write the change in the nonpreferred bidder's expected payoff from a marginal increase in his bid as

$$
\left.M U_{n}(v) \equiv\left[v-\eta(v)-\gamma R_{n}\left(v, \rho^{-1}(\eta(v)), v, v\right)\right] \rho^{-1 \prime}(\eta(v)) f_{p}\left(\rho^{-1}(\eta(v))\right)\right) .
$$

Now consider a deviation in the other direction. The change in the expected payoff of a nonpreferred bidder with value $v$ from decreasing his bid marginally below $\eta(v)$ is $-M U_{n}(v)$ minus an additional term that reflects the change in expected resale payoff associated with his being revealed to be a marginally lower type. Letting $\frac{d^{-}}{d x}$ denote the derivative from the left, we can write the change in the nonpreferred bidder's expected payoff from a marginal decrease in his bid below $\eta(v)$ as

$$
-M U_{n}(v)-\left.\gamma \frac{d^{-} R_{n}\left(v, \rho^{-1}(x), \eta^{-1}(x), \eta^{-1}(x)\right)}{d x}\right|_{x=\eta(v)}\left(1-F_{p}\left(\rho^{-1}(\eta(v))\right)\right) .
$$


The first term reflects the decreased probability of winning and the second term reflects the increase in the nonpreferred bidder's expected payoff from resale when he loses as a result of revealing himself to be a worse type $\left(\frac{d^{-} R_{n}}{d x}<0\right)$.

As one can see from a comparison of (1) and (2), it is not possible for both to simultaneously be equal to zero. If (1) is zero, then (2) is positive, which implies that the nonpreferred bidder has an incentive to deviate downward. Conversely, if (2) is zero, then (1) is positive, which implies that the nonpreferred bidder has an incentive to deviate upward. This "ratchet effect" whereby the nonpreferred bidder's bid provides a signal of his type means upward and downward deviations cannot simultaneously be deterred. ${ }^{18}$ Thus, we have the following result.

Proposition 1 When there is a positive probability of resale, there is no perfect Bayesian equilibrium in which the nonpreferred bidder's bid function is fully revealing over an open set of types.

Given the backdrop of Proposition 1, we focus on equilibria in which there is pooling by intervals of types of the nonpreferred bidder. Calling pooling by the types of nonpreferred bidder obfuscation, Proposition 1 has the following corollary.

Corollary 1 When there is a positive probability of resale, all perfect Bayesian equilibria involve obfuscation by the nonpreferred bidder.

When $\gamma>0$, by Proposition 1 and the observation that $\eta(0)=0$, in any equilibrium there exists $\hat{v}>0$ such that nonpreferred types in $[0, \hat{v})$ bid zero. This implies that the expected resale payoff for a preferred bidder with value zero from winning at a bid of zero is $\gamma R_{p}(0,0,0, \hat{v})>0$. Thus, sequential rationality implies that a preferred bidder with value zero bids a positive amount. This gives us the following result.

Proposition 2 When there is a positive probability of resale, all perfect Bayesian equilibria involve speculation by the preferred bidder.

Thus, equilibria involve pooling by types of nonpreferred bidders and positive bids by the lowest type of preferred bidder.

\section{$k$-step perfect Bayesian equilibria}

By Proposition 1, any perfect Bayesian equilibrium bid function for the nonpreferred bidder involves pooling by subintervals of types and can be characterized by an increasing step function. Sequential rationality implies that each type of preferred bidder remains active up to and only up to the price at which her expected payoff from winning at that price is zero, given the bid function of the nonpreferred bidder and updated beliefs regarding the nonpreferred bidder's value. This implies that perfect Bayesian equilibria involve step-function bidding by the nonpreferred bidder

\footnotetext{
${ }^{18}$ For more on the ratchet effect due to resale after auctions, see Lebrun (2010a) and Lebrun (2012), which consider, respectively, first-price and second-price auctions and deal with the ratchet effect by allowing mixed strategies.
} 
and a corresponding increasing, but discontinuous, bid function for the preferred bidder. Moreover, equilibrium requires that at each jump in the nonpreferred bidder's bid function, the nonpreferred bidder must be indifferent between the lower and higher bid. The nonpreferred bidder trades off a lower probability of winning coupled with a higher expected resale payoff associated with a lower bid against a higher probability of winning coupled with a lower expected resale payoff associated with a higher bid. ${ }^{19}$

By Proposition 1, for $\gamma>0$, equilibria can be described by the number $k \in\{0,1, \ldots\}$ of positive pooling bids for the nonpreferred bidder, the cutoffs types for the pooling regions for the nonpreferred bidder $0=\tau_{k+1}<\tau_{k}<\ldots<\tau_{1}<\tau_{0}=\bar{v}$, and the associated bids for the nonpreferred bidder $0=\eta_{k+1}<\eta_{k}<\ldots<\eta_{1}<\eta_{0}$. Thus, given parameters $(\boldsymbol{\eta}, \boldsymbol{\tau})$, where $\boldsymbol{\eta}=\left(\eta_{0}, \ldots, \eta_{k+1}\right)$ and $\boldsymbol{\tau}=\left(\tau_{0}, \ldots, \tau_{k+1}\right)$, the nonpreferred bidder's bid function is

$$
\eta(v ; \boldsymbol{\tau}, \boldsymbol{\eta})= \begin{cases}\eta_{k+1}=0, & \text { if } 0 \leq v<\tau_{k} \\ \eta_{k}, & \text { if } \tau_{k} \leq v<\tau_{k-1} \\ \ldots & \ldots \\ \eta_{1}, & \text { if } \tau_{1} \leq v<\tau_{0} \\ \eta_{0}, & \text { if } v=\tau_{0} .\end{cases}
$$

Bids by the nonpreferred bidder that are between the equilibrium bids of $0, \eta_{k}, \ldots, \eta_{0}$ or that are greater than $\eta_{0}$ are off the equilibrium path. We assume that when the preferred bidder observes a bid by the nonpreferred bidder of $b \in\left(\eta_{i+1}, \eta_{i}\right)$ for $i \in\{1, \ldots, k\}$, she believes that the nonpreferred bidder's value is confined to $\left[\tau_{i}, \tau_{i-1}\right)$. Thus, the preferred bidder believes that off-equilibrium bids by the nonpreferred bidder come from a bidder whose value is in the range associated with the next higher bid. If the preferred bidder observes a bid greater than $\eta_{1}$ (including off-equilibrium bids in $\left(\eta_{1}, \eta_{0}\right)$ and greater than $\eta_{0}$, as well as the on-equilibrium bid of $\left.\eta_{0}\right)$, she believes that the nonpreferred bidder has value $\bar{v}$. We refer to these beliefs as forward-looking beliefs because active bidding by the nonpreferred bidder that exceeds one of the equilibrium pooling bids causes the preferred bidder to believe that the nonpreferred bidder's value falls in one of the higher pooling intervals, and an exit by the nonpreferred bidder at a price that exceeds one of the equilibrium pooling bids but is below the next one, causes the preferred bidder to believe that the nonpreferred bidder's value falls in the next higher pooling interval.

Under forward-looking beliefs, the preferred bidder never "unlearns" what she already has inferred about that nonpreferred bidder's value. These beliefs make deviations by the nonpreferred bidder unprofitable because upward deviations to off-equilibrium bids induce disadvantageous resale offers by the preferred bidder, while downward deviations to off-equilibrium bids reduce the probability of winning without improving resale offers relative to the next higher equilibrium bid.

The preferred bidder's payoff is zero if she does not win the auction. Thus, sequential ratio-

\footnotetext{
${ }^{19}$ This is reminiscent of the tradeoff defining the indifference condition for the incumbent in the limit-pricing model of Harrington (1986). In the two-period version of the model in that paper, an incumbent firm faces the tradeoff between a higher first-period payoff that does not deter entry, and thereby reduces the second-period payoff, and a lower first-period payoff that deters entry and hence increases the second-period payoff.
} 
nality requires that the preferred bidder exit at a bid equal to her willingness to pay given the nonpreferred bidder's strategy and her forward-looking beliefs, which implies that her bid function has discontinuities whenever the bid reaches one of the nonpreferred bidder's pooling bids:

$$
\rho(v ; \boldsymbol{\tau}, \boldsymbol{\eta})= \begin{cases}\rho_{k}(v), & \text { if } \rho_{k}(v) \leq \eta_{k} \\ \rho_{k-1}(v), & \text { if } \rho_{k}(v)>\eta_{k} \text { and } \rho_{k-1}(v) \leq \eta_{k-1} \\ \ldots & \ldots \\ \rho_{i-1}(v) & \text { if } \rho_{k}(v)>\eta_{k}, \ldots, \rho_{i}(v)>\eta_{i}, \text { and } \rho_{i-1}(v) \leq \eta_{i-1} \\ \ldots & \ldots \\ \rho_{0}(v), & \text { if } \rho_{k}(v)>\eta_{k}, \ldots, \rho_{1}(v)>\eta_{1},\end{cases}
$$

where for $i \in\{1, \ldots, k\}$ (we suppress the dependence of $\rho_{i}$ on $\tau$ ),

$$
\rho_{i}(v) \equiv \frac{1}{1-c}\left(v+\gamma R_{p}\left(v, v, \tau_{i}, \tau_{i-1}\right)\right)
$$

and where

$$
\rho_{0}(v) \equiv \frac{1}{1-c}\left(v+\gamma R_{p}(v, v, \bar{v}, \bar{v})\right) .
$$

The overall bid function $\rho$ increases continuously from $\rho_{k}(0)$, which is positive when $\gamma>0$, up to a bid of $\eta_{k}$, but then because the beliefs about the type of the preferred bidder change discontinuously as the bid increases above $\eta_{k}$, the bid of the preferred bidder jumps up and then continues to increase continuously according to $\rho_{k-1}(\cdot)$ until the bid of $\eta_{k-1}$, etc. After the jump at the bid of $\eta_{1}$, the bid function continues according to $\rho_{0}(\cdot)$ until the bid of $\rho_{0}(\bar{v})=\frac{1}{1-c} \bar{v}$. When the preferred bidder has value $v$ and $\rho_{i}(v) \in\left(\eta_{i+1}, \eta_{i}\right]$, then a bid of $\rho_{i}(v)$ is sequentially rational because it is equal to the expected payoff to a preferred bidder with value $v$ given that winning at such a bid reveals that the nonpreferred bidder's value is in $\left[\tau_{i}, \tau_{i-1}\right)$.

Although the preferred bidder's bid function is discontinuous, and so certain bids are off the equilibrium path (e.g., bids between zero and $\rho_{k}(0)$ and between $\eta_{i}$ and $\rho_{i-1}\left(\rho_{i}^{-1}\left(\eta_{i}\right)\right)$ for $i \in$ $\{1, \ldots, k\})$, such bids are only revealed when the nonpreferred bidder wins, in which case there is no resale and so no role for beliefs.

An implication of forward-looking beliefs is that $\eta_{i} \leq \tau_{i}$ for all $i \in\{0, \ldots, k\}$ so that in equilibrium a nonpreferred bidder never bids above his value. To see this, note that if, to the contrary, $\eta_{i}>\tau_{i}$, then the bid strategy of (3) would specify that a nonpreferred bidder with value $\tau_{i}$ should bid $\eta_{i}$, which would be above his value. However, a nonpreferred bidder with value $\tau_{i}$ would prefer to bid $\tau_{i}$ rather than $\eta_{i}$ even though the preferred bidder's inference would be the same (that his value is in $\left[\tau_{i}, \tau_{i+1}\right)$ ) because he would avoid losses associated with winning at a price above his value, which occurs with positive probability at the nonpreferred bidder's positive equilibrium bids.

We summarize with the following proposition.

Proposition 3 When there is a positive probability of resale, all perfect Bayesian equilibria with forward-looking beliefs are $k$-step equilibria characterized by nonnegative integer $k$, nonpreferred 
bidder's equilibrium bids $\boldsymbol{\eta}=\left(\eta_{0}, \ldots, \eta_{k+1}\right)$ satisfying $0=\eta_{k+1}<\eta_{k}<\ldots<\eta_{1}<\eta_{0}<\bar{v}$, cutoffs for the nonpreferred bidder's pooling regions $\boldsymbol{\tau}=\left(\tau_{0}, \ldots, \tau_{k+1}\right)$ satisfying $0=\tau_{k+1}<\tau_{k}<\ldots<\tau_{1}<$ $\tau_{0}=\bar{v}$ and $\eta_{i} \leq \tau_{i}$ for all $i \in\{0, \ldots, k\}$, and nonpreferred and preferred bid functions (3) and (4).

In what follows, we continue to focus on the equilibrium concept of perfect Bayesian equilibria with forward-looking beliefs, which we refer to simply as equilibria.

\section{Characterization of equilibria}

Although Proposition 3 shows that all perfect Bayesian equilibria with forward-looking beliefs are $k$-step equilibria, the equilibrium is not necessarily unique. In some cases there may be $k$-step equilibria with different numbers of steps and multiple equilibria with the same number of steps. Despite this multiplicity of equilibria, we are able to obtain results on the effects of changes in the probability of resale because equilibrium outcomes are essentially unique both when the probability of resale is zero and when the probability of resale is sufficiently high that only equilibria with complete obfuscation (0-step equilibria) exist. It is only for relatively low but positive values for the probability of resale that the multiplicity of equilibria create challenges for characterizing outcomes. We address the multiplicity of equilibria in more detail in Section 4 where we provide bounds on equilibrium outcomes.

We begin by characterizing when an equilibrium exists with $k=0$, which we refer to as an equilibrium with complete obfuscation. In such an equilibrium, all types of the nonpreferred bidder, except possibly the highest type, bid zero, and the preferred bidder wins with probability one. Thus, complete obfuscation equilibria are essentially unique. We then provide conditions for the existence of $k$-step equilibria more generally.

It will be useful to define the expected continuation payoff of the nonpreferred bidder given the current price level in the auction. These definitions take the number of steps $k$ and nonpreferred bid levels and pooling regions $\boldsymbol{\eta}$ and $\boldsymbol{\tau}$ as given. To conserve on notation, we drop these as arguments of $\rho$. Although $\rho(0)>0$ when there is a positive probability of resale, and so the range of $\rho$ on domain $[0, \bar{v}]$ does not include zero, it will be convenient in what follows to define $\rho^{-1}(0) \equiv 0$.

Define $\pi_{0}^{\rho}(v, b)$ to be the expected payoff of a nonpreferred bidder with value $v$ if he bids $b$, conditional on the bid having reached $\eta_{1}$ and given that the preferred bidder bids according to $\rho$ :

$$
\begin{aligned}
\pi_{0}^{\rho}(v, b) \equiv & E_{v^{\prime} \mid F_{p}}\left[v-\rho\left(v^{\prime}\right) \mid \rho^{-1}\left(\eta_{1}\right) \leq v^{\prime} \leq \rho^{-1}(b)\right] \operatorname{Pr}_{v^{\prime} \mid F_{p}}\left(v^{\prime}<\rho^{-1}(b) \mid \rho^{-1}\left(\eta_{1}\right) \leq v^{\prime}\right) \\
& +\gamma R_{n}\left(v, \rho^{-1}(b), \bar{v}, \bar{v}\right) \operatorname{Pr}_{v^{\prime} \mid F_{p}}\left(\rho^{-1}(b) \leq v^{\prime} \mid \rho^{-1}\left(\eta_{1}\right) \leq v^{\prime}\right)
\end{aligned}
$$

where the first term on the right is the expected payoff when the nonpreferred bidder wins, times the probability of winning conditional on reaching $\eta_{1}$, and the second term on the right is the expected payoff from resale when the nonpreferred bidder loses, times the probability of losing conditional on reaching $\eta_{1}$. 
Define $b^{*}(v ; \rho)$ to maximize $\pi_{0}^{\rho}(v, b)$, i.e.,

$$
b^{*}(v ; \rho) \in \arg \max _{b \in\left[\eta_{1}, \bar{v}\right]} \pi_{0}^{\rho}(v, b) .
$$

For $i \in\{1, \ldots, k\}$, define $\pi_{i}^{\rho}(v)$ to be the expected payoff of a nonpreferred bidder with value $v$ if he remains active up to $\eta_{i}$, conditional on the bid having reached $\eta_{i+1}$ and given that the preferred bidder bids according to $\rho$ :

$$
\begin{aligned}
\pi_{i}^{\rho}(v) \equiv & E_{v^{\prime} \mid F_{p}}\left[v-\rho\left(v^{\prime}\right) \mid \rho^{-1}\left(\eta_{i+1}\right) \leq v^{\prime} \leq \rho^{-1}\left(\eta_{i}\right)\right] \operatorname{Pr}_{v^{\prime} \mid F_{p}}\left(v^{\prime} \leq \rho^{-1}\left(\eta_{i}\right) \mid \rho^{-1}\left(\eta_{i+1}\right) \leq v^{\prime}\right) \\
& +\gamma R_{n}\left(v, \rho^{-1}\left(\eta_{i}\right), \tau_{i}, \tau_{i-1}\right) \operatorname{Pr}_{v^{\prime} \mid F_{p}}\left(\rho^{-1}\left(\eta_{i}\right)<v^{\prime} \mid \rho^{-1}\left(\eta_{i+1}\right) \leq v^{\prime}\right),
\end{aligned}
$$

where the terms have an analogous interpretation as in (5).

An equilibrium with complete obfuscation exists if and only if all types of the nonpreferred bidder weakly prefer to bid zero and lose with probability one rather than bid any positive amount, given that the preferred bidder bids according to $\rho_{0}(v)=\frac{1}{1-c}\left(v+\gamma R_{p}(v, v, \bar{v}, \bar{v})\right)$, which is sequentially rational for the preferred bidder given complete obfuscation by the nonpreferred bidder and the forward-looking beliefs. The nonpreferred bidder with value $v$ has expected payoff from resale after he exits at a bid of zero of $\gamma R_{n}(v, 0,0, \bar{v})$, and he has expected payoff from a positive bid that is bounded above by $\pi_{0}^{\rho_{0}}\left(v, b^{*}(v)\right)$ (we drop the argument $\rho_{0}$ in $b^{*}\left(v ; \rho_{0}\right)$ and in what follows where the relevant bid function is clear). If for all $v \in[0, \bar{v}], \gamma R_{n}(v, 0,0, \bar{v}) \geq \pi_{0}^{\rho_{0}}\left(v, b^{*}(v)\right)$, then, and only then, do all types of nonpreferred bidder weakly prefer to bid zero rather than any positive amount, giving an equilibrium with complete obfuscation. When an equilibrium with complete obfuscation exists, it is essentially uniquely defined. Specifically, if the inequality above holds strictly at $\bar{v}$, then the equilibrium is unique. If it holds with equality at $\bar{v}$, then the equilibrium is unique up to the bid of the nonpreferred bidder with value $\bar{v}$, which can be either 0 or $b^{*}(\bar{v})$ in equilibrium.

We summarize with the following proposition.

Proposition 4 There exists an equilibrium with complete obfuscation if and only if for all $v \in[0, \bar{v}]$,

$$
\gamma R_{n}(v, 0,0, \bar{v}) \geq \pi_{0}^{\rho_{0}}\left(v, b^{*}(v)\right)
$$

and if such an equilibrium exists, it is essentially uniquely defined and has $\eta_{0}=b^{*}(\bar{v})$.

As we show in the next proposition, under certain conditions on the underlying distributions and parameters (which hold in the setup of Section 3.2), it is sufficient to check the condition of Proposition 4 only for the nonpreferred bidder with value $\bar{v}$.

Proposition 5 If $\gamma R_{n}(v, 0,0, \bar{v})-\pi_{0}^{\rho_{0}}\left(v, b^{*}(v)\right)$ is concave in $v$ when it is nonzero, then there exists an equilibrium with complete obfuscation if and only if

$$
\gamma R_{n}(\bar{v}, 0,0, \bar{v}) \geq \pi_{0}^{\rho_{0}}\left(\bar{v}, b^{*}(\bar{v})\right)
$$


Proof. See Appendix A.

The condition for the existence of an equilibrium with complete obfuscation, (6), holds for $c$ sufficiently large. In particular, if $c$ is so large that the preferred bidder with value zero is willing to bid above $\bar{v}$, then complete obfuscation is the only equilibrium - the nonpreferred bidder prefers to bid zero rather than reveal information regarding his value given that he is certain to lose. In addition, the required threshold for $c$ decreases with $\gamma$ because as $\gamma$ increases, the value of resale to the nonpreferred bidder with value $\bar{v}$, who has a higher expected payoff from obfuscation (whereby he loses with probability one but, to his advantage in resale, maximally obscures his value), increases relative to any positive bid, given that a positive bid would cause the preferred bidder to believe him to be of type $\bar{v}$.

Proposition 6 For probability of resale $\gamma$ and bid credit $c$ sufficiently close to one, the unique equilibrium has complete obfuscation.

The following proposition characterizes the existence of equilibrium with incomplete obfuscation.

Proposition 7 A k-step equilibrium characterized by $\boldsymbol{\eta}$ and $\boldsymbol{\tau}$ and bid functions (3) and (4) exists if and only if $\boldsymbol{\eta}$ and $\boldsymbol{\tau}$ satisfy the conditions of Proposition 3 with $\eta_{0}=b^{*}(\bar{v})$ and (i) for all $v \in\left[\tau_{1}, \tau_{0}\right]$

$$
\gamma R_{n}\left(v, \rho^{-1}\left(\eta_{1}\right), \tau_{1}, \tau_{0}\right) \geq \pi_{0}^{\rho}\left(v, b^{*}(v)\right),
$$

and (ii) for all $i \in\{1, \ldots, k\}$ and $v \in\left[\tau_{i+1}, \tau_{i}\right]$,

$$
\gamma R_{n}\left(v, \rho^{-1}\left(\eta_{i+1}\right), \tau_{i+1}, \tau_{i}\right) \geq \pi_{i}^{\rho}(v)
$$

with equality for $v=\tau_{i}$.

Proof. See Appendix A.

The first condition in Proposition 7 says that conditional on the bid reaching $\eta_{1}$, a nonpreferred bidder with value $v \in\left[\tau_{1}, \tau_{0}\right]$ weakly prefers to exit at $\eta_{1}$, thereby pooling with nonpreferred bidders with values in $\left[\tau_{1}, \tau_{0}\right)$, rather than remaining active above $\eta_{1}$ and being believed to have value $\bar{v}$. The second condition says that for any $i \in\{1, \ldots, k\}$, conditional on the bid reaching $\eta_{i+1}$, a nonpreferred bidder with value $v \in\left[\tau_{i+1}, \tau_{i}\right)$ weakly prefers to exit at $\eta_{i+1}$, thereby pooling with nonpreferred bidders with values in $\left[\tau_{i+1}, \tau_{i}\right)$, rather than remaining active up to $\eta_{i}$, thereby pooling with nonpreferred bidders with values in $\left[\tau_{i}, \tau_{i-1}\right)$. Finally, for $i \in\{1, \ldots, k\}$, a nonpreferred bidder with value $\tau_{i}$ must be indifferent between exiting at $\eta_{i+1}$ and remaining active up to $\eta_{i}$.

Similar to the case of complete obfuscation, under a concavity condition, the equilibrium conditions of Proposition 7 are implied by conditions defined only in terms of the cutoff types for the nonpreferred bidder. Given a candidate $k$-step equilibrium characterized by $\boldsymbol{\eta}$ and $\boldsymbol{\tau}$, we say that 
step concavity is satisfied if $\gamma R_{n}\left(v, \rho_{0}^{-1}\left(\eta_{1}\right), \tau_{1}, \tau_{0}\right)-\pi_{0}^{\rho_{0}}\left(v, b^{*}(v)\right)$ is concave in $v$ for all $v \in[0, \bar{v}]$ when it is nonzero, and for all $i \in\{i, \ldots, k\}, \gamma R_{n}\left(v, \rho_{i}^{-1}\left(\eta_{i+1}\right), \tau_{i+1}, \tau_{i}\right)-\pi_{i}^{\rho_{i}}(v)$ is concave in $v$ for all $v \in\left[0, \tau_{i}\right]$ when it is nonzero. This condition is satisfied in the example based on uniformly distributed types given in Section 4 .

Proposition 8 Given $\boldsymbol{\eta}$ and $\boldsymbol{\tau}$ that satisfy the conditions of Proposition 3 for a $k$-step equilibrium, with $\eta_{0}=b^{*}(\bar{v})$, if step concavity is satisfied, then $\boldsymbol{\eta}$ and $\boldsymbol{\tau}$ define a $k$-step equilibrium if

$$
\gamma R_{n}\left(\bar{v}, \rho^{-1}\left(\eta_{1}\right), \tau_{1}, \bar{v}\right) \geq \pi_{0}^{\rho}\left(\bar{v}, b^{*}(\bar{v})\right)
$$

and for all $i \in\{1, \ldots, k\}$,

$$
\gamma R_{n}\left(\tau_{i}, \rho^{-1}\left(\eta_{i+1}\right), \tau_{i+1}, \tau_{i}\right)=\pi_{i}^{\rho}\left(\tau_{i}\right)
$$

Proof. See Appendix A.

If an equilibrium with complete obfuscation does not exist, then some positive number of steps are required. For example, consider the conditions under which a one-step equilibrium exists. As shown in Proposition 7 , a one-step equilibrium $(k=1)$ is defined by $\eta_{1}$ and $\tau_{1}$, which define the height and length, respectively, of the single positive step in the nonpreferred bidder's bid function. These parameters must satisfy $(7)$ and, for $i=1,(8)$. Because in a one-step equilibrium $\rho^{-1}\left(\eta_{2}\right)=0$ and $\tau_{2}=0$, (8) depends only on $\tau_{1}$ and $\eta_{1}$ and so (8) defines a set of $\left(\tau_{1}, \eta_{1}\right)$ pairs. If (7) is not satisfied for any of these pairs, then no one-step equilibrium exists. When step concavity is satisfied, a one-step equilibrium exists for each $\left(\tau_{1}, \eta_{1}\right)$ pair that also satisfies $(7)$.

Using Proposition 7, we can provide a sufficient condition for when all equilibria involve complete obfuscation by noting that in any $k$-step equilibrium with $k \geq 1$ there must be a $k$-th step (the first step up starting from the left) defined by $\tau_{k}$ and $\eta_{k} \leq \tau_{k}$. That step must satisfy (8): $\gamma R_{n}\left(\tau_{k}, 0,0, \tau_{k}\right)=\pi_{k}^{\rho}\left(\tau_{k}\right)$, where $\pi_{k}^{\rho}\left(\tau_{k}\right)$ depends on $\eta_{k}, \tau_{k}$, and $\tau_{k-1}$, and is nondecreasing in $\tau_{k-1}$. Thus, the required indifference condition cannot be satisfied if for all $\tau_{k} \in(0,1)$,

$$
\gamma R_{n}\left(\tau_{k}, 0,0, \tau_{k}\right)<\max _{\eta_{k} \in\left(0, \tau_{k}\right]} \pi_{k}^{\rho \text { s.t. } \tau_{k-1}=\bar{v}}\left(\tau_{k}\right)
$$

giving us the following result.

Corollary 2 If (6) holds and (9) holds for all $\tau_{1} \in(0,1)$, then all equilibria involve complete obfuscation.

For $k \geq 1$, equilibrium is defined by $\eta_{1}, \ldots, \eta_{k}$ and $\tau_{1}, \ldots, \tau_{k}$, so there are $2 k$ parameters but only $k+1$ equilibrium conditions, one of which is an equality: (7) and (8) for $i \in\{1, \ldots, k\}$. Thus, for $k \geq 1$, there is some flexibility to define longer, lower steps versus shorter, higher steps while still maintaining the equilibrium conditions of Proposition 7. We explore this multiplicity in more detail in the following section. 


\section{Multiplicity of equilibria}

In this section, we explore the issue of multiplicity of equilibria. We focus on the case of values drawn from the uniform distribution on $[0,1]$ and a resale game in which each bidder is equally likely to make the resale offer $(\lambda=0.5) .{ }^{20}$ In addition, we assume a $20 \%$ bid credit. In this case, all equilibria involve complete obfuscation for $\gamma$ greater than a cutoff $\gamma^{*}$ that is approximately 0.6.

For a probability of resale slightly below $\gamma^{*}$, 1-step equilibria exist, but 2-step equilibria do not. In particular, for $\gamma$ slightly below $\gamma^{*}$, we can find all the equilibria by finding all $\left(\tau_{1}, \eta_{1}\right)$ pairs that satisfy (8) for $k=1$ and $i=1$ and then selecting those pairs that satisfy (7). This is illustrated in Figure 2(a) for the case of $\gamma=0.55$. In that case, the probability of resale is sufficiently low that an equilibrium with complete obfuscation does not exist; however, 1-step equilibria do exist.

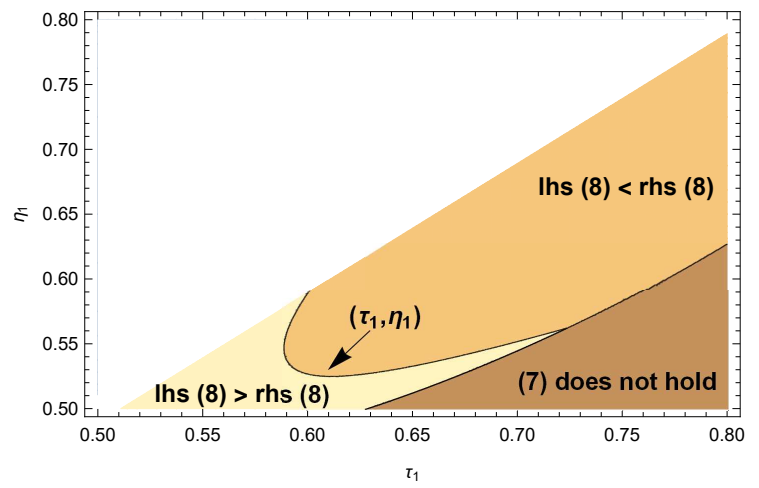

(a) Equations (7) and (8) with $i=1$ for a one-step equilibrium

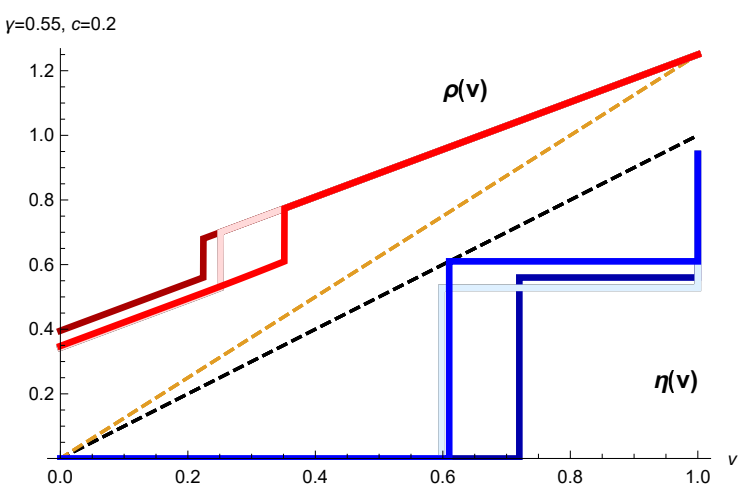

(b) Range of equilibrium bid functions

Figure 2: Illustration of equilibrium bid functions for $\gamma=0.55$ assuming a $20 \%$ bid credit, values are drawn from the uniform distribution on $[0,1]$, and resale with 50-50 randomized take-it-or-leave-it offers. In panel (b), equally shaded bid functions constitute one equilibrium.

We graph the equilibrium bid functions in Figure 2(b). While there are multiple values for the length and height of the step that satisfy the equilibrium conditions, Figure 2(b) shows the equilibrium bid functions with the most extreme values for $\tau_{1}$ and $\eta_{1}$ among all of the equilibria. Thus, although there are a continuum of equilibria, the equilibrium bid functions are bounded by

${ }^{20}$ In the uniform case, we can write the resale payoffs as follows: For $v>\hat{v}$ and $\ell \leq h$,

$$
R_{n}(v, \hat{v}, \ell, h)=\lambda \frac{1}{1-\hat{v}} \int_{\hat{v}}^{\bar{v}} \max \left\{0, v-\max \left\{\ell, \frac{v_{p}+h}{2}\right\}\right\} d v_{p}+(1-\lambda)\left(\max \left\{0, \frac{v-\hat{v}}{2}\right\}\right)^{2} \frac{1}{1-\hat{v}}
$$

where the first term is zero if $v=\ell$. For $v<h$ and $\ell<h$,

$$
R_{p}(v, \hat{v}, \ell, h)=\lambda\left(\max \left\{\ell, \frac{v+h}{2}\right\}-v\right) \frac{h-\max \left\{\ell, \frac{v+h}{2}\right\}}{h-\ell}+(1-\lambda) \frac{1}{h-\ell} \int_{\ell}^{h} \max \left\{0, \frac{v_{n}+\hat{v}}{2}-v\right\} d v_{n},
$$

and for $v<h$,

$$
R_{p}(v, \hat{v}, h, h)=\lambda(h-v)+(1-\lambda) \max \left\{0, \frac{h+\hat{v}}{2}-v\right\} .
$$


the ones shown in the figure.

In the equilibria shown in Figure 2(b), nonpreferred bidders with sufficiently low values bid zero. However, if the probability of resale were to decrease, then a bid of zero by a nonpreferred bidder, which only generates a positive payoff when resale occurs, would become increasingly unattractive, especially to a nonpreferred bidder with a high value. Thus, as the probability of resale decreases, a larger range of nonpreferred bidders prefer to pool at a positive bid rather than at a bid of zero, eventually requiring more steps in order to satisfy the equilibrium conditions. Although Figure 2 focuses on a particular case of bidders who draw their types from the same uniform distribution, the progression through $k$-step equilibria with increasing numbers of steps as the probability of resale decreases is a general phenomenon.

Although the multiplicity of equilibria create a multiplicity of possible equilibrium outcomes such as social surplus, we can place bounds on these effects too. Outcomes are unique when $\gamma=0$ or when all equilibria involve complete obfuscation. For the intermediate range of values for the probability of resale, social surplus is bounded above by the social surplus associated with the "truthful" bid functions illustrated in Figure 1 and bounded below by the social surplus associated with bid functions that involve complete obfuscation. We illustrate equilibrium outcomes and upper and lower bounds for social surplus in Figure 3. As shown in the figure, once the probability of resale is sufficiently large that there is complete obfuscation, social surplus increases in the probability of resale. However, as one moves from no resale to a probability of resale sufficiently high that there is complete obfuscation, social surplus decreases. Thus, the relation between social surplus and the probability of resale is nonmonotonic in this case. We characterize more generally when such nonmonotonicity occurs in the next section.

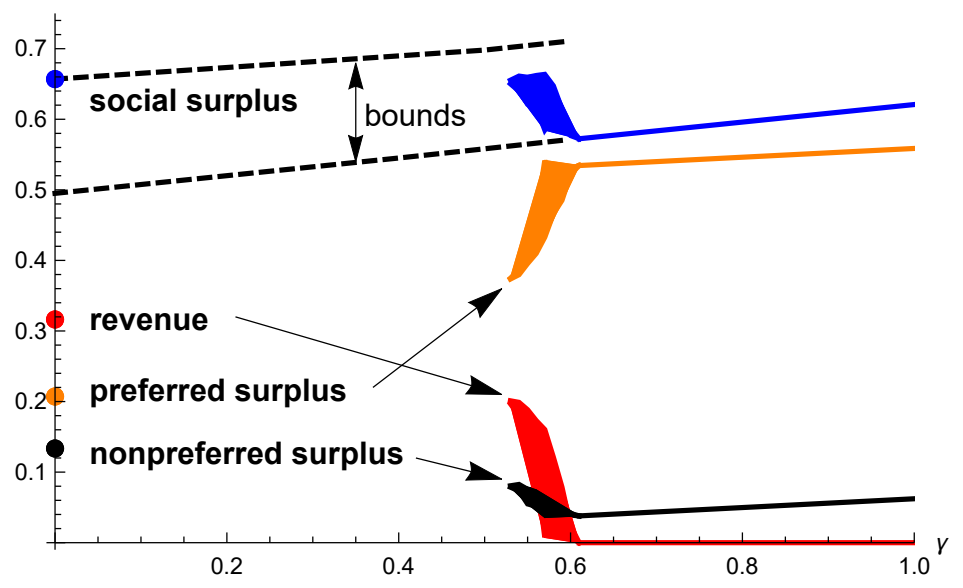

Figure 3: Auction outcomes for different values of the probability of resale, $\gamma$. For $\gamma=0$, dots indicate the unique outcomes, and for $\gamma$ greater than approximately 0.6 , lines indicate the unique outcomes. For values of $\gamma$ in a range below 0.6, we show the convex hull of outcomes for all equilibria (based on a grid of size 0.01). Upper and lower bounds are indicated for social surplus for intermediate values of $\gamma$. Assumes a 20\% bid credit, with values drawn from the uniform distribution on $[0,1]$ and 50-50 randomized take-it-or-leave-it offers in resale. 
In the specification underlying Figure 3, the nonpreferred bidder prefers no resale $(\gamma=0)$ to the case of frictionless matching in the resale market $(\gamma=1)$. Although the absence of resale precludes the nonpreferred bidder from buying the object on the secondary market, resale increases the aggressiveness of bidding by the preferred bidder sufficiently that the nonpreferred bidder is better off without resale.

Furthermore, Figure 3 shows that, despite the multiplicity of equilibria for intermediate values of the probability of resale, robust comparative statics are available for revenue and for the surplus of the preferred and nonpreferred bidders because the upper and lower bounds defining the regions in which those equilibrium outcomes lie are themselves monotonic. In the multiplicity region illustrated in Figure 3, expected revenue and nonpreferred surplus are decreasing in the probability of resale and expected preferred surplus is increasing in the probability of resale.

\section{$5 \quad$ Welfare effects}

In this section, we return to the general setup without restricting $\lambda$ or the distributions and focus on the welfare effects of changes in the probability of resale, with welfare being defined as the expected social surplus associated with the allocation after the resale game. As we show, some of the effects identified in the previous section for the special case of the uniform distribution hold more generally.

Given a preferred bidder with value $v_{p}$ and a nonpreferred bidder with value $v_{n}$, the auction outcome is ex post efficient if the higher valuing bidder holds the item after the resale game. In that case there are no gains from resale. When $v_{n} \leq v_{p}$, the auction outcome is efficient because the preferred bidder - who has the higher value - always wins in those cases. The auction outcome is also ex post efficient when $\rho\left(v_{p}\right)<\eta\left(v_{n}\right)$ because then the nonpreferred bidder has the higher value and the higher bid. In these cases, there is no scope or need for post-auction transactions. However, when $v_{n}>v_{p}$ and $\rho\left(v_{p}\right) \geq \eta\left(v_{n}\right)$, the auction outcome is not ex post efficient.

Figure 4 illustrates these regions in $\left(v_{n}, v_{p}\right)$ space for the case of bid credits and the probability of resale sufficiently large that the unique equilibrium involves complete obfuscation. Although the figure is drawn for a particular specification of distributions and parameters, our regularity assumptions on the distributions ensure that the regions depicted in the figure apply generally whenever the equilibrium involves complete obfuscation.

In area $A$, the preferred bidder has the higher value and wins the auction, giving an efficient outcome. In area $F$, the object remains inefficiently with the preferred bidder regardless of who makes the resale offer. In areas $B$ and $C$, the preferred bidder has the lower value but still wins the auction. In area $B$, the nonpreferred bidder purchases the object in resale with probability $\gamma \lambda$, i.e., only when resale occurs and the preferred bidder makes the offer - when the nonpreferred bidder makes the offer, he makes an offer below the preferred bidder's value, so the offer is rejected. In area $C$, the nonpreferred bidder purchases the object in resale with probability $\gamma$, i.e., when resale

occurs, regardless of who makes the offer. In area $E$, where $v_{n} \geq \Phi^{-1}\left(v_{p} ; \bar{v}\right)$ and $v_{p} \leq \Gamma^{-1}\left(v_{n} ; 0\right)$, the 
object changes hands in resale only if the nonpreferred bidder makes the offer, i.e., with probability $\gamma(1-\lambda)$.

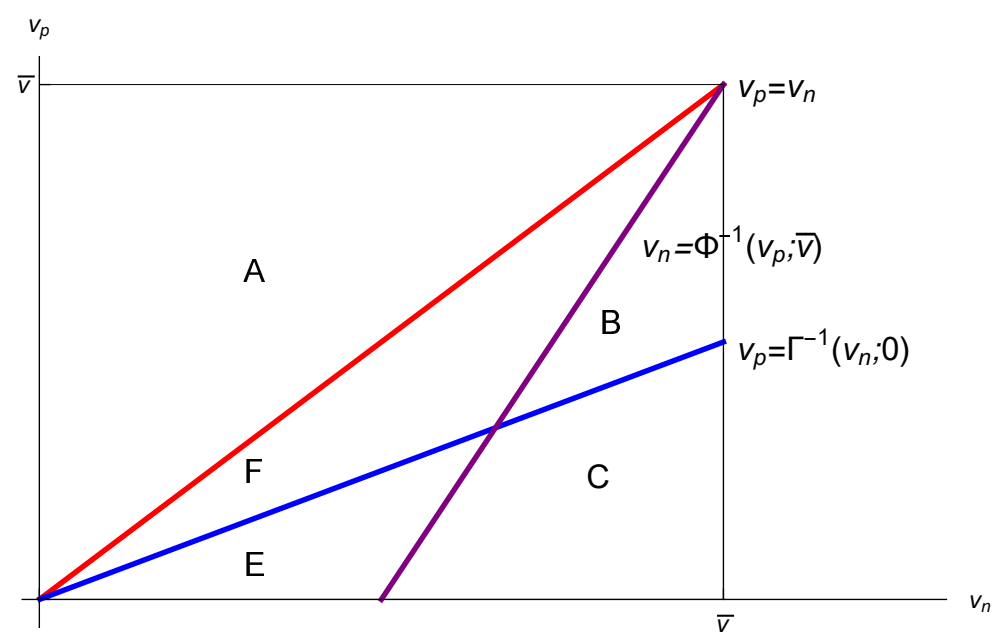

Figure 4: Welfare with complete obfuscation. Area A: efficient auction outcome; B: efficient outcome with probability $\gamma \lambda$; C: efficient outcome with probability $\gamma$; E: efficient outcome with probability $\gamma(1-\lambda)$; F: inefficient outcome. Curves drawn for the case of $c=0.2$ and $\gamma=0.7$, with values drawn from the uniform distribution on $[0,1]$ and 50-50 take-it-or-leave-it offers in resale.

Writing out the expressions for welfare associated with Figure 4, in the case of complete obfuscation, the expected welfare generated by the auction plus resale conditional on the nonpreferred and preferred bidders' values is

$$
w\left(v_{n}, v_{p}\right)= \begin{cases}v_{p}, & \text { if }\left(v_{n}, v_{p}\right) \in A \cup F \\ v_{p}+\gamma \lambda\left(v_{n}-v_{p}\right), & \text { if }\left(v_{n}, v_{p}\right) \in B \\ v_{p}+\gamma\left(v_{n}-v_{p}\right), & \text { if }\left(v_{n}, v_{p}\right) \in C \\ v_{p}+\gamma(1-\lambda)\left(v_{n}-v_{p}\right), & \text { if }\left(v_{n}, v_{p}\right) \in E .\end{cases}
$$

When obfuscation is not complete, there is an additional region within region $C$ with $\left(v_{n}, v_{p}\right)$ such that $v_{p} \leq \rho^{-1}\left(\eta\left(v_{n}\right)\right)$. This region consists of high values for the nonpreferred bidder and low values for the preferred bidder such that the nonpreferred bidder wins the object, which is efficient. Consequently, there is no resale and welfare is $v_{n}$ in this region.

We can characterize how welfare changes with increases in the probability of resale once that probability is sufficiently high that equilibria involve complete obfuscation. With complete obfuscation, expected welfare is $W(c, \gamma) \equiv E\left[w\left(v_{n}, v_{p}\right)\right]$. The direct effect of resale on welfare, which consists of the derivative of $W(c, \gamma)$ with respect to $\gamma$, not taking into account the effects on $\eta$ and $\rho$ and how these affect the five regions, is positive. The total effect of resale on welfare also accounts for the effects on $\eta$ and $\rho$. However, in an equilibrium with complete obfuscation the probability of resale does not affect the bidding strategies, so in this case welfare is increasing in the probability 
of resale. ${ }^{21}$

Proposition 9 Given an equilibrium with complete obfuscation, $W(c, \gamma)$ increases with increases in $\gamma$.

Because the equilibrium with complete obfuscation is unique for $\gamma$ and $c$ sufficiently large, Proposition 9 implies that welfare is increasing in the probability of resale in these cases. This corresponds to the upward sloping welfare line in Figure 3 for $\gamma$ sufficiently large.

We can also contrast welfare in the unique equilibrium when there is no resale $(\gamma=0)$ with the unique equilibrium when $\gamma$ is sufficiently large that there is complete obfuscation. When $\gamma=0$, welfare is $v_{p}$ for all $\left(v_{n}, v_{p}\right) \in G \equiv\left\{\left(v_{n}, v_{p}\right) \mid v_{p} /(1-c) \geq v_{n}\right\}$, and welfare is $v_{n}$ otherwise, i.e., for $\left(v_{n}, v_{p}\right) \in \bar{G}$, where $\bar{G}$ is the complement to $G$. Assuming that the bid credit is such that $G \cap(C \cup E)$ has zero measure (i.e., for all $v \in[0, \bar{v}],(1-c) v \geq \Gamma^{-1}(v ; 0)$ ), then relative to the case of $\gamma=1$, when $\gamma=0$, welfare is the same in regions $A, C$, and $F \cap G$. We need only consider changes in welfare in the regions $F \cap \bar{G}, B \cap \bar{G}, B \cap G$, and $E$. Relative to the case of $\gamma=1$, when $\gamma=0$, welfare increases from $v_{p}$ to $v_{n}$ in $F \cap \bar{G}$, increases from $v_{p}+\lambda\left(v_{n}-v_{p}\right)$ to $v_{n}$ in $B \cap \bar{G}$, decreases from $v_{p}+\lambda\left(v_{n}-v_{p}\right)$ to $v_{p}$ in $B \cap G$, and increases from $v_{p}+(1-\lambda)\left(v_{n}-v_{p}\right)$ to $v_{n}$ in region $E$. Thus, the only region of decrease is $B \cap \bar{G}$, and the amount of that decrease vanishes with $\lambda$. Thus, we have the following result.

Proposition 10 Given $c$ such that for all $v \in[0, \bar{v}],(1-c) v \geq \Gamma^{-1}(v ; 0)$, for $\lambda$ sufficiently close to zero, $W(c, 0)>W(c, 1)$.

Put in words, Proposition 10 says that for $\lambda$ small enough, welfare is greater when there is no resale than when there is resale with probability one. This nonmonotonic relation between welfare and the probability of resale arises because when resale occurs with probability one equilibrium in the auction involves complete obfuscation. Proposition 10 thus provides general conditions under which we obtain the result apparent in Figure 3 that welfare is higher when $\gamma=0$ than when $\gamma=1$. Under the conditions of Proposition 10, even though resale corrects some of the inefficiency in the auction allocation due to the use of bid credits, a designer whose objective is total welfare, and whose choice set involves only no resale or resale with probability one, may prefer to prohibit resale rather than allow it. Of course, in a dynamic environment, the efficient allocation of assets may evolve over time, in which case the option of resale transactions offers benefits.

In addition, the combination of Propositions 10 and 9 provides an interesting implication. Suppose there is a designer whose objective is to maximize expected welfare. Suppose that the designer takes the bid credit as given but can choose from a limited range of values for the probability of resale, perhaps by making design choices for the item that affect its transferability or through regulation restricting resale. If the bid credit and range of resale probabilities are such that the

\footnotetext{
${ }^{21}$ In general, resale affects the equilibrium bidding strategies of preferred and nonpreferred bidders, so overall effects are more complicated. Referring to Figure 4 , as $\gamma$ increases, area $B$ increases at the expense of area $C$, which decreases welfare. At the same time, however, the expected payoff for types in area $B \cup C$ increases, which increases welfare.
} 
equilibrium always has complete obfuscation, such as when the bid credit is large, then Proposition 9 implies that the designer prefers the largest feasible probability of resale. However, if the bid credit if sufficiently small that equilibria do not involve complete obfuscation, by Proposition 10 the designer may prefer the lowest feasible probability of resale.

\section{Remedies}

The analysis above shows that, because bid credits induce inefficient auction outcomes some of the time, they create scope for post-auction resale, and that by inducing additional distortions into equilibrium bidding, the prospect of post-auction resale exacerbates the inefficiency of the auction outcome. In fact, it is possible that, if anticipated, facilitating post-auction resale can decrease overall surplus. This raises the question as to possible remedies, which we address next.

Before doing so, it is useful to distinguish between the seller (or owner) of the asset and the auction designer, which we take to be different entities, and their objectives. We assume that the designer, which can be thought of as a government agency in charge of specifying the rules of the auction and of running the auction, wants to maximize social surplus while the seller, which can be thought of as Congress, imposes bid credits because of other, possibly political, motives. We think this is a plausible description of some auctions with bid credits. It is, of course, conceivable that bid credits are imposed in the pursuit of socially desirable goals such as fostering competition downstream. Given such an objective, one could then analyze optimal bid credits, anticipating equilibrium bidding and post-auction resale. However, such an analysis is beyond the scope of the present paper but a fruitful avenue for future research. In the discussion below, we first ask what the seller could do to better achieve his goals and then address how the designer may be able to reduce the inefficiencies associated with bid credits.

\subsection{Give-aways}

An alternative approach to bid credits is to give the asset to the preferred bidder for free and allow the preferred bidder to run an optimal auction. ${ }^{22}$ Clearly, for $\gamma$ or $c$ sufficiently large that there is complete obfuscation by the nonpreferred bidder, this is equivalent to running an auction with bid credits followed by resale. The use of give-aways makes the enrichment of the preferred bidder painstakingly clear, whereas auctions with bid credits give the appearance of a more even playing field even though they fail on that dimension when bid credits are large enough and resale easy enough.

\footnotetext{
${ }^{22}$ Another alternative would be to create a Myerson-Satterthwaite setup in which the mechanism designer charges a fee as in Loertscher and Niedermayer (2016) and thereby implements the constrained efficient mechanism (with weight on revenue and either only the preferred bidder's welfare or both bidders' welfare).
} 


\subsection{Reserve prices}

The equilibrium bid functions characterized above can be adjusted to accommodate a positive reserve. With a positive reserve, the preferred bidder's incentive for speculative bidding is reduced because the preferred bidder needs a sufficiently high value in order to be willing to bid above the reserve. When the reserve is positive, a nonpreferred bidder with value greater than the reserve has a reduced incentive for obfuscating bidding because that could result in the object not being sold at all. Instead the nonpreferred bidder may prefer to pool at a bid equal to the reserve rather than at a bid of zero.

In the auction with a positive reserve, we assume that the price increases from zero but, even if only one active bidder remains, does not stop until it reaches the reserve. This is consistent with the use of reserves in, for example, FCC auctions, where the minimum opening bid is frequently less than the reserve.

When there is complete obfuscation with no reserve, the adjustment for a positive reserve involves defining two cutoff values, $v_{p}^{r}$ for the preferred bidder and $v_{n}^{r}$ for the nonpreferred bidder. With a positive reserve, the preferred bidder bids below the reserve for values less than $v_{p}^{r}$, but bids according to $\rho$ for values greater than $v_{p}^{r}$. The nonpreferred bidder bids zero for values less than $v_{n}^{r}$ and bids the reserve for values between $v_{n}^{r}$ and $\bar{v}$.

Proposition 11 When there is complete obfuscation in the absence of a reserve, the imposition of a reserve $r$ results in an equilibrium characterized by

$$
\hat{\rho}(v)=\left\{\begin{array}{ll}
v, & \text { if } v<v_{p}^{r} \\
\rho(v), & \text { otherwise, }
\end{array} \quad \text { and } \hat{\eta}(v)= \begin{cases}0, & \text { if } v<v_{n}^{r} \\
r, & \text { if } v_{n}^{r} \leq v<\bar{v} \\
\eta(\bar{v}), & \text { otherwise, }\end{cases}\right.
$$

where $\rho$ and $\eta$ are the equilibrium bid functions in the absence of a reserve and where $v_{p}^{r} \in$ $\left[\rho^{-1}(r),(1-c) r\right]$ and $v_{n}^{r} \geq 0$ are defined by

$$
\begin{aligned}
0= & E_{v \mid F_{n}}\left[v_{p}^{r}-r(1-c)+\gamma R_{p}\left(v_{p}^{r}, 0,0, v_{n}^{r}\right) \mid v<v_{n}^{r}\right] \underset{v \mid F_{n}}{\operatorname{Pr}}\left(v<v_{n}^{r}\right) \\
& +E_{v \mid F_{n}}\left[v_{p}^{r}-r(1-c)+\gamma R_{p}\left(v_{p}^{r}, v_{p}^{r}, v_{n}^{r}, \bar{v}\right) \mid v_{n}^{r} \leq v\right] \underset{v \mid F_{n}}{\operatorname{Pr}}\left(v_{n}^{r} \leq v\right)
\end{aligned}
$$

and

$$
\begin{aligned}
\gamma R_{n}\left(v_{n}^{r}, 0,0, v_{n}^{r}\right)= & E_{v \mid F_{p}}\left[v_{n}^{r}-r \mid v \leq v_{p}^{r}\right] \underset{v \mid F_{p}}{\operatorname{Pr}}\left(v<v_{p}^{r}\right) \\
& +\gamma E_{v \mid F_{p}}\left[R_{n}\left(v_{n}^{r}, v_{p}^{r}, v_{n}^{r}, \bar{v}\right) \mid v_{p}^{r}<v\right] \underset{v \mid F_{p}}{\operatorname{Pr}}\left(v_{p}^{r} \leq v\right) .
\end{aligned}
$$

Proof. See Appendix A.

Below we illustrate the effect of adding a reserve when the equilibrium without a reserve involves complete obfuscation. As shown in Figure 5, the preferred bidder no longer prefers to win the object 
for a range of low values, and the nonpreferred bidder prefers to pool at the reserve rather than at zero for sufficiently high values.

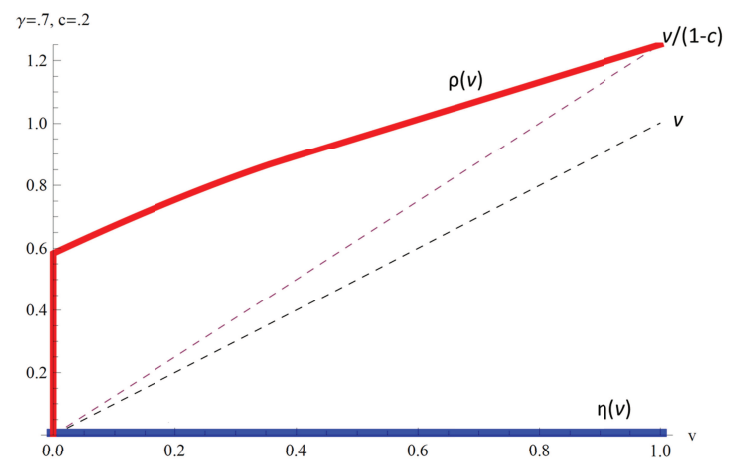

(a) No reserve

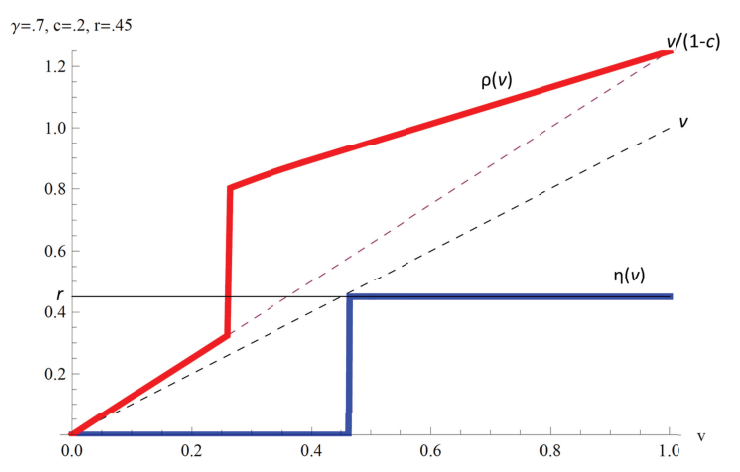

(b) Reserve of 0.45

Figure 5: Bid functions for the case of a $70 \%$ chance of resale and a $20 \%$ bid credit (assuming values are drawn from the uniform distribution on $[0,1]$ and 50-50 randomized take-it-or-leave-it offers in resale)

For an auction with bid credits and a sufficiently high probability of resale, the addition of a positive reserve may improve the efficiency despite creating the possibility that the object is not sold at all. Both the efficiency of the auction improves and the efficiency of the resale market improves because there is less obfuscation. Of course, when both bidders have low values, the object may go unsold, which is the usual source of inefficiency associated with a positive reserve. ${ }^{23}$

\subsection{Credit caps}

Another possibility to limit the effects of bid credits is to impose a cap on the absolute value of the credit that a bidder may get. For example, the FCC has most recently established a $\$ 150$ million cap for the dollar value of the credit that a winning preferred bidder can receive. ${ }^{24}$ Our model extends easily to allow for such credit caps. Obviously a low cap mitigates or eliminates the adverse effects of bid credits - in the extreme, a cap of $\$ 0$ eliminates all effects of bid credits - but as shown next, large caps do not qualitatively affect our results. In particular, complete obfuscation can occur in equilibrium when there is resale, rendering credit caps ineffective, even when the cap is tight enough to improve outcomes without resale. The analysis thus shows that credit caps may be an effective instrument to limit the adverse effects of bid credits, but it also emphasizes the importance of accounting for resale markets in the context of auctions with bid credits.

Consider a cap $\kappa$ on bid credits, so that the credit received by a preferred bidder who wins at price $b$ is $\min \{c b, \kappa\}$. In the absence of resale, a preferred bidder's bid function with a cap is

\footnotetext{
${ }^{23}$ For an example in which a positive reserve increases efficiency, for the case of a $20 \%$ bid credit and resale probability $\gamma=0.7$ (assuming uniform distributions and 50-50 randomized take-it-or-leave-it offers in the resale market), an auction with no reserve achieves $89 \%$ of maximum welfare, whereas an auction with a reserve of $r=0.45$ does slightly better, achieving $90 \%$ of maximum welfare.

${ }^{24}$ See Section II.B.3 of the FCC's "Competitive Bidding" Report and Order cited in footnote 8.
} 
$\bar{\rho}(v)=\min \{v /(1-c), v+\kappa\}$, so that $\bar{\rho}(v)=\frac{v}{1-c}$ for $v \leq \kappa \frac{1-c}{c}$ and $\bar{\rho}(v)=v+\kappa$ otherwise. Thus, the cap, when it binds, reduces the extent to which the preferred bidder is willing to bid above her value. A tight cap can reduce overbidding by preferred bidders and underbidding by nonpreferred bidders, relative to their values, and may prevent complete obfuscation. In this case, the imposition of the cap increases expected revenue and expected total welfare. It decreases the expected surplus of the preferred bidder and increases that of the nonpreferred bidder.

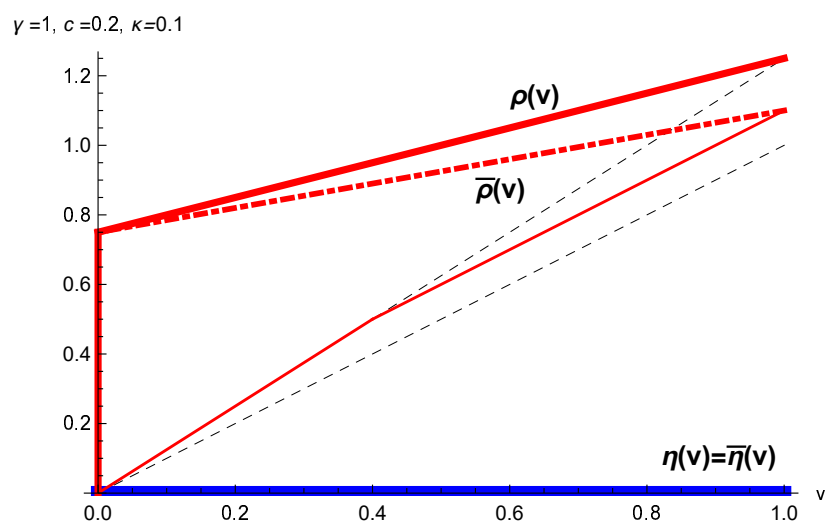

Figure 6: Bid functions without a cap $(\rho$ and $\eta)$ and with a cap of $\kappa=0.1(\bar{\rho}$ and $\bar{\eta})$. The case shown is for complete obfuscation with $\gamma=1$, where the preferred bidder's bid function with the cap but with no resale is shown as a thin, solid line. Assumes a $20 \%$ bid credit, values that are drawn from the uniform distribution on $[0,1]$, and 50-50 randomized take-it-or-leave-it offers in resale.

However, a cap that binds in the absence of resale need not have any moderating effect when resale is possible. For example, consider parameters such that, in the absence of a cap, resale results in complete obfuscation. If the cap satisfies $\kappa<\frac{c}{1-c} \bar{v}$, then the cap binds in the absence of resale (which is illustrated as the thin, unbroken line in Figure 6), but the equilibrium with the cap continues to have complete obfuscation. In the case of complete obfuscation, a nonpreferred bidder with value $\bar{v}$ is indifferent between bidding $\eta(\bar{v})$ and zero, and a nonpreferred bidder with value less than $\bar{v}$ strictly prefer to bid zero.

As illustrated in Figure 6, for $\gamma$ sufficiently large, a cap does not affect the fact that the nonpreferred bidder bids zero whatever his value and that the preferred bidder bids a positive amount, even when her value is zero, although her maximum bid is altered to be $\min \left\{\frac{\bar{v}}{1-c}, \bar{v}+\kappa\right\}$. Thus, the imposition of such a cap does not get rid of complete obfuscation in equilibrium. Consequently, the credit cap is ineffective in the presence of resale even though it improves social surplus (and designer's revenue) absent resale.

\subsection{Anonymous bidding with multiple bidders}

We now show how the results of Section 3.2 adapt to a setting with multiple preferred or nonpreferred bidders. In this setting, a difference arises depending on whether bidders can observe the 
exit points of their rivals, so we also discuss the impact of observable versus anonymous bidding. ${ }^{25}$

To analyze the case of multiple bidders of each kind with observable bidding, we assume that bidders can exit immediately after one another, so that if one bidder is observed to exit at a bid of $b$, then other bidders observing that can also exit at a bid of $b$, but with the order of exits being observable. In the resale game, we assume that a winning preferred bidder negotiates with the last remaining nonpreferred bidder.

First consider the case of one preferred bidder and multiple nonpreferred bidders. In the observable bidding case, the nonpreferred bidders remain active up to their values as long as another nonpreferred bidder is active because exiting when another nonpreferred bidder is active guarantees a payoff of zero, whereas winning at a bid that is below a bidder's value generates a positive payoff. ${ }^{26}$ If the second-to-last nonpreferred bidder exits at $b$, then the final nonpreferred bidder with value $v$ also exits if $\eta(v)<b$, and otherwise remains active up to $\eta(v)$. Thus, there is pooling by a range of types for the highest-valuing nonpreferred bidder at the value of the second-highestvaluing nonpreferred bidder. The preferred bidder bids more conservatively than when facing only one nonpreferred bidder, i.e., according to some $\tilde{\rho}(v) \in\left(\frac{v}{1-c}, \rho(v)\right)$, until only one nonpreferred bidder remains, and then bids up to $\rho(v)$. The more aggressive bidding by the nonpreferred bidders when multiple nonpreferred bidders are active reduces the expected resale payoff of the preferred bidder in the event that she wins.

In the case of one nonpreferred bidder and multiple preferred bidders, preferred bidders bid according to $\rho$ until the last nonpreferred bidder exits. At this point, assuming $\rho$ is a $k$-step bid function, the expected resale payoff for a preferred bidder that has value $v$ and wins at a bid of $b$ such that for some $i \in\{1, \ldots, k\}, \eta\left(\tau_{i}\right)<b \leq \eta\left(\tau_{i-1}\right)$, is $R\left(v, \rho^{-1}(b), \tau_{i-1}, \tau_{i-2}\right)$, with $\tau_{-1} \equiv \bar{v}$. Thus, following the exit of the last nonpreferred bidder at a bid revealing his value to be in $\left[\tau_{i-1}, \tau_{i-2}\right)$, the preferred bidders remain active up to $b$ such that $b=\frac{1}{1-c}\left(v+\gamma R\left(v, \rho^{-1}(b), \tau_{i-1}, \tau_{i-2}\right)\right)$. The nonpreferred bidder bids closer to truthfully than he does facing only one preferred bidder, i.e., according to some $\tilde{\eta}(v) \in(\eta(v), v)$, until only one preferred bidder remains and then bids according to $\eta(v)$. This occurs because the expected payoff to a nonpreferred bidder from resale is lower if multiple preferred bidders remain active.

We assume that under anonymous bidding bidders observe nothing during the auction except the price. As long as the price continues to increase, active bidders can thus infer that at least one other bidder is active as well. At the conclusion of the auction, the exit points of all of the bidders are made public. This means that in the resale game a winning preferred bidder can identify the highest-bidding nonpreferred bidder.

\footnotetext{
${ }^{25}$ For example, in the current FCC spectrum license auction format, bidders observe how many other bidders are active, but they do not observe their identities until after the auction is complete, at which time the full history of bids is made public.

${ }^{26} \mathrm{In} \mathrm{Hu}$, Kagel, $\mathrm{Xu}$, and Ye (2013), it is also the case that bidding strategies depend on whether another bidder of the same type remains active. In the model of that paper, two incumbents and a potential entrant compete at an auction, but there is an externality imposed on both incumbents if the entrant wins. In equilibrium, an incumbent has an incentive to exit earlier when the other incumbent is active, free riding on the other incumbent's incentive to bid so as to exclude the entrant.
} 
Given the assumptions just stated, with one preferred and one nonpreferred bidder, equilibrium behavior is the same whether bidding is anonymous or not. With one preferred and two or more nonpreferred bidders, the payoff maximization problem for the preferred bidder is structurally the same (although with a different distribution) as when there is only one nonpreferred bidder. However, for the nonpreferred bidders, the maximization problem is different because a nonpreferred bidder must take into account the need to beat the other nonpreferred bidders in order to benefit from resale. This implies that anonymous bidding is closer to "truthful" in the sense that the preferred bid function is closer to $\frac{v}{1-c}$ and the nonpreferred bid function is closer to $v$.

Similarly, anonymous bidding mutes incentives for speculative and counterspeculative bidding when there are multiple bidders of each type. The intuition is that a bidder's beliefs about the remaining active bidders will, for certain bid ranges, place positive weight on there being other bidders of his or her own kind. For example, with multiple preferred bidders, as the bid increases, there is increasing probability that the bid has increased beyond the exit point of the last nonpreferred bidder, in which case the expected gains from resale by the winning preferred bidder decrease. This reduces incentives for speculation. To the extent that anonymity in the auction reduces the expected value to bidders from resale, this leads to bid functions that are closer to the bid functions without resale, which increases the expected efficiency of the auction outcome. ${ }^{27}$

\section{Alternative auction formats}

Although the preceding analysis has focused on ascending auctions, the results of Sections 3.2 and 5 apply equally to second-price sealed bid auctions. However, when there are multiple preferred and nonpreferred bidders, the observation of exit by competing bidders in the open format can be informative about the types of the remaining bidders, and so differences arise between open ascending and sealed-bid formats. In this case, the second-price sealed-bid auction corresponds to the case of anonymous bidding in an ascending auction described in Section 6 .

The results of Section 3.2 can also be restated for the case of a procurement organized as a descending auction. If a bid credit takes the form of a percentage increase in the payment made to a preferred bidder who has the lowest bid, and if subcontracting is possible, then preferred bidders have an incentive to shade their bids downward and nonpreferred bidders have an incentive to shade their bids upward. Thus, when subcontracting is possible, bid credits lead to inefficiencies whereby a preferred bidder may win the procurement auction even though she does not have the lowest cost. The winning preferred bidder has an incentive to subcontract to a lower cost bidder, profiting from the markup to the procurer.

\footnotetext{
${ }^{27}$ Marx (2006) discusses other reasons why anonymous bidding may improve the efficiency of auction outcomes in the context of multiple object auctions.
} 


\section{Conclusion}

Bid credits are widely used in auctions and procurements. Favouring some bidders over others, bid credits induce inefficient auction outcomes with positive probability, which creates scope and pressure for post-auction resale or, in the procurement context, for subcontracting. Although such post-auction transactions unambiguously improve social outcomes if they are not anticipated by bidders in the auction, our equilibrium analysis shows that when post-auction transactions are anticipated by bidders, auction outcomes are made unambiguously less efficient.

Because the prospect of post-auction transactions increases the value of winning for the preferred bidder and the value of losing for the nonpreferred bidder, the possibility of resale or subcontracting induces speculative and counterspeculative bidding by the preferred and the nonpreferred bidder, respectively. This makes the auction less efficient and means that the prospect of post-auction transactions reinforces the desirability of such transactions. Moreover, because the counterspeculative bid shading by the nonpreferred bidder is more likely to obfuscate his value the higher is the probability that the resale market operates, an increase in the probability that the resale market operates can decrease the total surplus that is generated from the auction and the resale market. Thus, the prospect of post-auction transactions makes such transactions more desirable to correct inefficient auction outcomes but less effective at doing so because of obfuscation.

We analyze a number of remedies that may mitigate the inefficiencies associated with bid credits and resale or subcontracting. One possible remedy is the imposition of caps on the absolute dollar amount a preferred bidder may be credited for. As a case in point, such caps have recently been introduced by the FCC. Our analysis reveals that such caps unambiguously improve outcomes without resale or subcontracting, provided they bind some of the time. If chosen tight enough, they also do so with resale and subcontracting. However, even if a cap improves outcomes without the possibility of post-auction transactions, the same cap may be completely ineffective with resale or subcontracting if it is not tight enough to overcome complete obfuscation.

Throughout the paper, we have maintained the view that bid credits are exogenously imposed, hindering the socially efficient allocation of resources. This is arguably an appropriate perspective in some instances and circumstances. However, it is also plausible and possible that bid credits are imposed to achieve desirable social goals such as inducing a competitive market structure downstream. When viewed from this angle, our paper provides the first step toward an integrated analysis of optimal bid credits by analyzing the subgame that ensues after bid credits have been determined. Analyzing the full game, for which our paper delivers the equilibrium analysis for the second stage, seems an excellent avenue for future research. 


\section{A Appendix: Proofs}

Proof of Proposition 5. An implication of Proposition 4 is that there exists an equilibrium with complete obfuscation only if $\gamma R_{n}(\bar{v}, 0,0, \bar{v})-\pi_{0}^{\rho_{0}}\left(\bar{v}, b^{*}(\bar{v})\right) \geq 0$, so (6) is necessary. Suppose that $\gamma R_{n}(v, 0,0, \bar{v})-\pi_{0}^{\rho_{0}}\left(v, b^{*}(v)\right)$ is concave in $v$ and that $(6)$ holds. Because $\gamma R_{n}(0,0,0, \bar{v})=$ $\pi_{0}^{\rho_{0}}\left(0, b^{*}(0)\right)$, it then follows that for all $v \in[0, \bar{v}], \gamma R_{n}(v, 0,0, \bar{v}) \geq \pi_{0}^{\rho_{0}}\left(v, b^{*}(v)\right)$, which is sufficient for an equilibrium with complete obfuscation.

Proof of Proposition 7. The preferred bidder's strategy $\rho$ is defined so as to be sequentially rational given $\eta$. Conditions (7) and (8) guarantee that a nonpreferred bidder with value $v \in\left[\tau_{i+1}, \tau_{i}\right]$ weakly prefers to bid $\eta_{i+1}$ rather than $\eta_{i}$, with the bidder with value $\tau_{i}$ being indifferent, except that a nonpreferred bidder with value and $\bar{v}$ may prefer bidding $\eta_{1}$ over and $\eta_{0}$. Given the off-equilibrium beliefs for the preferred bidder defined above, the nonpreferred bidder with value $v \in\left[\tau_{i+1}, \tau_{i}\right]$ also weakly prefers $\eta_{i+1}$ to any lower or higher off-equilibrium-path bid.

Proof of Proposition 8. If (7) and (8) hold, then by step concavity and the observation that $\gamma R_{n}\left(v, \rho_{0}^{-1}\left(\eta_{1}\right), \tau_{1}, \tau_{0}\right)-\pi_{0}^{\rho_{0}}\left(v, b^{*}(v)\right)$ and $\gamma R_{n}\left(v, \rho_{i}^{-1}\left(\eta_{i+1}\right), \tau_{i+1}, \tau_{i}\right)-\pi_{i}^{\rho_{i}}(v)$ are zero for $v=$ 0 , then for or all $v \in\left[\tau_{1}, \tau_{0}\right], \gamma R_{n}\left(v, \rho^{-1}\left(\eta_{1}\right), \tau_{1}, \tau_{0}\right) \geq \pi_{0}^{\rho}\left(v, b^{*}(v)\right)$ and for all $v \in\left[\tau_{i+1}, \tau_{i}\right]$, $\gamma R_{n}\left(v, \rho^{-1}\left(\eta_{i+1}\right), \tau_{i+1}, \tau_{i}\right) \geq \pi_{i}^{\rho}(v)$, which implies an equilibrium by Proposition 7 .

Proof of Proposition 11. Taking as given the strategy of the nonpreferred bidder, the expected payoff to a preferred bidder with value $v_{p}$ from bidding $\rho\left(v_{p}\right)>r$ is given by the right side of (10). As shown in that expression, the preferred bidder wins and pays $r(1-c)$ if $v_{n}<\eta^{-1}(r)$, where $v_{n}$ is the nonpreferred bidder's value, and otherwise wins when $\eta\left(v_{n}\right)<\rho\left(v_{p}\right)$ and pays $\eta\left(v_{n}\right)(1-c)$. The bidding reveals whether $v_{n}$ is in $\left[0, v_{n}^{r}\right),\left[v_{n}^{r}, \eta^{-1}(r)\right)$, or reveals $v_{n}$ for $v_{n}>\eta^{-1}(r)$. Equation (10) says that a preferred bidder with value $v_{p}^{r}$ is indifferent between bidding $v_{p}^{r} /(1-c)$, which is less than $r$ and loses with probability one, and bidding $\rho\left(v_{p}^{r}\right)$, which is greater than $r$.

Taking as given the strategy of the preferred bidder, the expected payoff from a nonpreferred bidder with value $v_{n}^{r}$ from bidding zero is $R_{n}\left(v_{n}^{r}, 0,0, v_{n}^{r}\right)$ because the bidder learns nothing about the preferred bidder's value and reveals that his value is bounded above by $v_{n}^{r}$. The expected payoff of a nonpreferred bidder with value $v_{n}^{r}$ from bidding $r$ is given by the right side of (11), where the first term occurs because the nonpreferred bidder wins at a price of $r$ if $v_{p}<v_{p}^{r}$, and the second term reflects the nonpreferred bidder's expected payoff from resale when the preferred bidder wins, i.e., $v_{p}>v_{p}^{r}$, with the bidding revealing that $v_{p}>v_{p}^{r}$ and that the nonpreferred bidder's value is less than $\eta^{-1}(r)$. Thus, equation (11) says that a nonpreferred bidder with value $v_{n}^{r}$ is indifferent between bidding zero and bidding $r$. One can show that equations (10) an (11) define $v_{p}^{r} \in\left[\rho^{-1}(r),(1-c) r\right]$ and $v_{n}^{r} \in[0, \bar{v}]$.

The result that it is a best response for a nonpreferred bidder with value $v$ greater than $\eta^{-1}(r)$ to bid $\eta(v)$ follows from $\eta$ being a best response in an environment with no reserve. 


\section{References}

Ausubel, L., and P. Cramton (2004): "Auctioning Many Divisible Goods," Journal of the European Economic Association, 2(2-3), 480-493.

Bulow, J., and J. Roberts (1989): "The Simple Economics of Optimal Auctions," Journal of Political Economics, 97(5), 1060-90.

Garratt, R., And T. Tröger (2006): "Speculation in Standard Auctions with Resale," Econometrica, 74(3), 753-769.

Garratt, R. J., T. Tröger, and C. Z. Zheng (2009): "Collusion via Resale," Econometrica, $77(4), 1095-1136$.

Gupta, M., And B. Lebrun (1999): "First Price Auctions with Resale," Economics Letters, 64(2), $181-185$.

HafaliR, I., And V. Krishna (2008): "Asymmetric Auctions with Resale," American Economic Review, 98(1), 87-112.

HafaliR, I., And V. Krishna (2009): "Revenue and Efficiency Effects of Resale in First-Price Auctions," Journal of Mathematical Economics, 45, 589-602.

Haile, P. A. (2000): "Partial Pooling at the Reserve Price in Auctions with Resale Opportunities," Games and Economic Behavior, 33, 231-248.

- (2001): "Auctions with Resale Markets: An Application to U.S. Forest Service Timber Sales," American Economic Review, 91, 399-427.

- (2003): "Auctions with Private Uncertainty and Resale Opportunities," Journal of Economic Theory, 108(1), 72-110.

Harrington, Joseph E., J. (1986): "Limit Pricing when the Potential Entrant is Uncertain of its Cost Function," Econometrica, 54(2), 429-437.

Hu, Y., J. Kagel, X. Xu, and L. Ye (2013): "Optimal Nonparametric Estimation of First-Price Auctions," Theoretical and Experimental Analysis of Auctions with Negative Externalities, 82, 269-291.

Lebrun, B. (2010a): "First-Price Auctions with Resale and with Outcomes Robust to Bid Disclosure," RAND Journal of Economics, 41(1), 165-178.

(2010b): "Revenue Ranking of First-Price Auctions with Resale," Journal of Economic Theory, 145, 2037-2043.

(2012): "Optimality and the English and Second-Price Auctions with Resale," Games and Economic Behavior, , 75(2), 731-751. 
Loertscher, S., And A. Niedermayer (2016): "Percentage Fees in Thin Markets: An Optimal Pricing Perspective," Mimeo, University of Mannheim and University of Melbourne.

Marion, J. (2007): "Are Bid Preferences Benign? The Effect of Sbusiness Subsidies in Highway Procurement Auctions," Journal of Public Economics, 91(7-8), 1591-1624.

Marx, L. M. (2006): "Economics at the Federal Communications Commission," Review of Industrial Organization, 29, 349-368.

McAfee, R. P., J. McMillan, and P. J. Reny (1989): "Extracting the Surplus in the CommonValue Auction.," Econometrica, 57(6), 1451-1459.

Milgrom, P., and R. Weber (1982): "A Theory of Auctions and Competitive Bidding," Econometrica, 50, 1089-1122.

Myerson, R. B. (1981): "Optimal Auction Design," Mathematical Operations Research, 6(1), $58-73$.

National Association of State Procurement Officials (2012): "2011-2012 NASPO Survey of State Procurement Practices Summary Report," available at http://naspo.org/survey/Documents/～Zip/FINAL_SummaryReport_2011-2012_Survey_6-2812.pdf, accessed October 27, 2014.

Pagnozzi, M. (2007): "Bidding to Lose? Auctions with Resale," RAND Journal of Economics, 38(4), 1090-1112.

- (2010): "Are Speculators Unwelcome in Multi-Object Auctions?," American Economic Journal: Microeconomics, 2(2), 97-131.

Pagnozzi, M., and K. J. Saral (2016a): "Efficiency in Auctions with (Failed) Resale," CSEF Working Paper No. 432.

— (2016b): "Entry by Successful Speculators in Auctions with Resale," Working Paper, University of Naples Federico II.

- (forthcoming): "Demand Reduction in Multi-Object Auctions with Resale: An Experimental Analysis,," Economic Journal.

Virginia Department of General Services - Division of Purchases and Supply (2010): "Listing of States' Absolute and Percentage Preferences," available at http://www.ilsr.org/wpcontent/uploads/2008/12/listing-states-preferences.pdf, accessed October 27, 2014.

Wilson, R. (1993): Nonlinear Pricing. Oxford University Press.

Xu, X., D. Levin, and L. Ye (2013): "Auctions with Entry and Resale," Games and Economic Behavior, 72, 92-105. 
Zhang, J., and R. Wang (2013): "Optimal Mechanism Design with Resale Via Bargaining," Journal of Economic Theory, 148, 2096-2123.

Zheng, C. Z. (2002): “Optimal Auction with Resale," Econometrica, 70(6), 2197-2224. 